\title{
A water risk index for portfolio exposure to climatic extremes: conceptualization and an application to the mining industry
}

\author{
Luc Bonnafous $^{1}$, Upmanu Lall ${ }^{1,2}$, and Jason Siegel ${ }^{2}$ \\ ${ }^{1}$ Columbia Water Center, Columbia University, New York, NY 10031, USA \\ ${ }^{2}$ Earth and Environmental Engineering Department, Columbia University, New York, NY 10031, USA \\ Correspondence to: Luc Bonnafous (lmb2216@columbia.edu)
}

Received: 29 September 2016 - Discussion started: 8 November 2016

Revised: 25 February 2017 - Accepted: 16 March 2017 - Published: 19 April 2017

\begin{abstract}
Corporations, industries and non-governmental organizations have become increasingly concerned with growing water risks in many parts of the world. Most of the focus has been on water scarcity and competition for the resource between agriculture, urban users, ecology and industry. However, water risks are multi-dimensional. Waterrelated hazards include flooding due to extreme rainfall, persistent drought and pollution, either due to industrial operations themselves, or to the failure of infrastructure. Most companies have risk management plans at each operational location to address these risks to a certain design level. The residual risk may or may not be managed, and is typically not quantified at a portfolio scale, i.e. across many sites. Given that climate is the driver of many of these extreme events, and there is evidence of quasi-periodic climate regimes at inter-annual and decadal timescales, it is possible that a portfolio is subject to persistent, multi-year exceedances of the design level. In other words, for a multi-national corporation, it is possible that there is correlation in the climateinduced portfolio water risk across its operational sites as multiple sites may experience a hazard beyond the design level in a given year. Therefore, from an investor's perspective, a need exists for a water risk index that allows for an exploration of the possible space and/or time clustering in exposure across many sites contained in a portfolio. This paper represents a first attempt to develop an index for financial exposure of a geographically diversified, global portfolio to the time-varying risk of climatic extremes using long daily global rainfall datasets derived from climate re-analysis models. Focusing on extreme daily rainfall amounts and using examples from major mining companies, we illustrate how the index can be developed. We discuss how companies
\end{abstract}

can use it to explore their corporate exposure, and what they may need to disclose to investors and regulators to promote transparency as to risk exposure and mitigation efforts. For the examples of mining companies provided, we note that the actual exposure is substantially higher than would be expected in the absence of space and time correlation of risk as is usually tacitly assumed. We also find evidence for the increasing exposure to climate-induced risk, and for decadal variability in exposure. The relative vulnerability of different portfolios to multiple extreme events in a given year is also demonstrated.

\section{Introduction}

Long-term investors, such as sovereign wealth funds, need to account for risks that may manifest themselves over several decades, and hence they may have a very different perspective on risk than short-term investors. In particular, they have a growing interest in understanding how climate and environmental risks may impact the companies comprising their investment portfolios. Scientific projections that climate change may increase the frequency and intensity of extreme rainfall and droughts amplify such concerns. Water-related risks dominate the pathways of exposure to climate variability and change. Consequently, many studies are being commissioned to "downscale" climate change projections to the level of cities or even individual assets as part of an environmental risk analysis. In the process, metrics and pathways of climate and water risk exposure at the asset level are reassessed, including, in some cases, past exposure and outcomes. 
However, site-specific data are often limited and regional climate may exhibit significant quasi-periodic or cyclical variability, with periods ranging from inter-annual (e.g. 3 to 7 years in the case of the El Niño-Southern Oscillation) to multi-decadal (e.g. 16-20 years for the Pacific Decadal Oscillation and 40-70 years for the Atlantic Multi-decadal Oscillation; see Frankcombe et al., 2010; McCabe and Palecki, 2006; Biondi, 2001; Knight et al., 2006; Gershunov and Barnett, 1998; Grimm and Tedeschi, 2009; Nicholson and Kim, 1997; Cayan et al., 1999; Risbey et al., 2009; Verdon et al., 2004; Kiem et al., 2003). Over the last century, facilities designed to deal with floods and droughts or to control pollution, as well as financial risk instruments such as insurance, have typically been designed with less than 30 years of at-site data. As illustrated in Fig. 1 and quantitatively demonstrated in Jain and Lall (2001), if the climate cycle shifts, an estimate of a 100-year event based on a specific 30 years of data may correspond to either a more frequent (e.g. 10-year) or rarer (e.g. 1000-year) event at the site in the succeeding 30 years when that instrument is actually used.

From a financial perspective, such regime-like behaviour is of interest. For a given asset, if the pre-design period corresponded to a wet regime, infrastructure could well be over designed, and the associated capital cost may negatively impact the project's economics. Conversely, if this period was lacking rainfall extremes, and if the next 10 years are expected to correspond to the regime with a high frequency of extreme rainfall, then production losses and reconstruction costs, even using a modest discount rate, may have a much higher than anticipated impact on the valuation of the mining asset. For an insurance contract, this would correspond to a clustering of payouts over that period. This may also translate into higher insurance rates, which may not be reduced as a transition to the regime occurs, whereby the frequency of extreme events goes down. Finally, in this scenario the investor may face a stranded asset, as the costs of reconstruction and liabilities caused by catastrophic failures may be prohibitive. Long climate records are needed to identify the temporal structure of the risk of extreme events, and to reflect it in subsequent risk analyses, so that appropriate estimates of the risk anticipated in the next decade or later can be made.

For the mining industry, depending on the duration and intensity of an extreme rainfall event, a cascade of direct and indirect financial impacts can result. These include

- production losses resulting from flooding of mine operations, loss of roadways, tailing dams, electricity services, equipment and/or housing;

- fines and clean-up costs, due to release of pollutants from tailing dams and from the site into waterbodies;

- increased costs related to dewatering procedures and new capital expenditure, pollution clean-up or even impacts on ecology, human health and casualties;

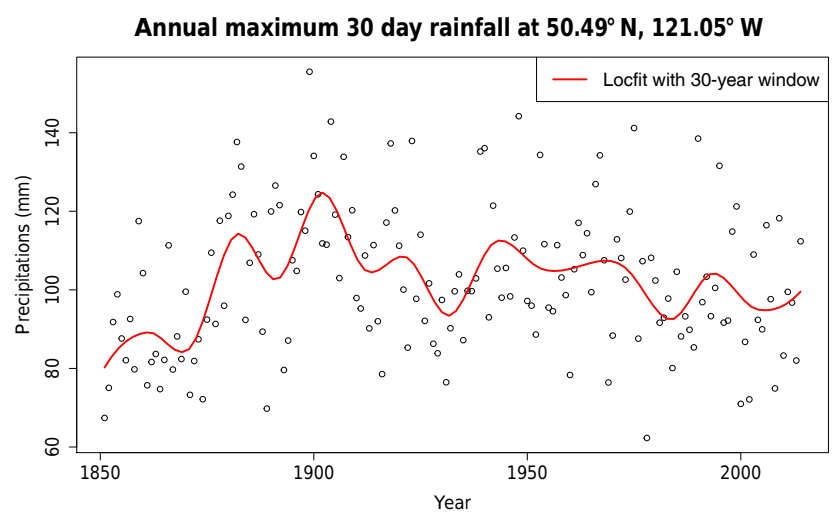

Figure 1. Time series of annual maximum 30-day precipitation for the Highland Valley open-pit copper mine in British Columbia, at latitude $50.49^{\circ} \mathrm{N}$, and longitude $121.05^{\circ} \mathrm{W}$, as estimated from the NOAA-CIRES 20th century climate re-analysis. This mine is one of the largest in the region, operating since the early 20th century. The highest precipitation for any consecutive 30-day period in each year is shown, together with a 30 -year-moving window regression to illustrate the trend.

- increases in insurance premiums;

- increased regulation, design standards and associated costs;

- asset stranding if restarting operations may be financially, politically or physically infeasible.

Some specific loss events may be insured, while others may not.

For example, in December 2010-January 2011, Queensland experienced heavy rainfall. This region has an active coal mining activity, with a complex system of mining assets and railways to bring coal to shipping ports. The event led to long dewatering processes, railway impairment, significant losses for mining companies and even spikes in coal prices (Chambers, 2011; Regan, 2011). Overall, Queensland coal production missed its target by 40 million tonnes in 2011 (Heber, 2013), and Australian production decreased for the first time since 1981 (BP, 2016). This contributed to a record price of USD 330 per tonne for hard coking coal (IBIS World, 2011; Bloomberg, 2011, 2015).

In February 1994, a $31 \mathrm{~m}$ high tailings dam at the Harmony Gold mine in South Africa failed due to overtopping following a heavy rainfall event (Van Niekerk and Viljoen, 2005). Nearly 300 houses were swept away or damaged, and 17 people were killed. The subsequent investigation of the disaster led to a reformulation of policies, design standards, and monitoring requirements for tailing dams. These have had an impact on the subsequent cost structure for managing such risks, but to our knowledge have not triggered a significant evaluation of the methods used to manage the residual risk from extreme rainfall events in the industry, other than 
the purchase of limited liability property and casualty, and business interruption insurance coverage.

The potential impact of extreme climate events is present even for mines not being actively operated, and may still exist for mines that stopped producing many years ago. Estimating potential damages associated with different levels of extreme hydrologic events at each mining site is difficult. Some companies are more financially exposed to these risks than others based on geography, exposure and mitigation strategies.

Moreover, for a portfolio that is composed of assets at many geospatial locations, one has to question whether the hydroclimatic risk factors are correlated across sites, such that many locations may experience floods or droughts in the same fiscal year, thus amplifying the impact of water and climate risks assessed for each site. A significant amount of research on the geographical impacts of the quasi-periodic climate variations suggests that many regions in the world can experience persistent changes in risk, depending on the phase of a climate oscillation. These regions may or may not be spatially contiguous. For instance, during an El Niño or a La Niña phase of the El Niño-Southern Oscillation, large parts of the world experience floods or droughts (Dai and Trenberth, 1998). A portfolio risk analysis of exposure to climate and water risks consequently needs to integrate over both the space and time structures of climate to account for clustering in the exposure to these risks, rather than considering them to be independent in time and space.

Many companies have started commissioning consultant reports as to their carbon and water footprints, and more recently to their risk projected for various IPCC climate change scenarios to the year 2050 or 2100 (Rajczak et al., 2016). Unfortunately, the current generation of models of the coupled ocean-atmosphere circulation, i.e. global climate models, when applied to the conditions of the 20th century, fails to reproduce the type of memory and oscillatory behaviour, as well as the spatial correlation structure, which is noted in long observational records. Further, basic statistics (e.g. mean, standard deviation and skew) of hydroclimatic extremes tend to be strongly biased relative to the 20th century observations in most locations in the world (Woldemeskel et al., 2012). An industry focused on bias corrections of these statistics and the use of these corrections for future projections has evolved. A popular and potentially effective approach for "correcting" such biases is quantile mapping (Rajczak et al., 2016), where the probability distribution of daily rainfall from an IPCC model for a historical period is scaled, quantile by quantile, to match the probability distribution of rainfall recorded as historical data at a particular location. This mapping is then extrapolated to the future period, a procedure whose reliability cannot be tested until the future occurs, since we do not know the source of the bias in the models used, and how that would propagate under extrapolation to a higher greenhouse forcing. Such point-by-point bias correction methods are thus not able to address the biases in long-term quasi-periodic evolution of climate, and do not constitute a reliable approach to future risk analysis since they represent a brute force attempt to correct and extrapolate selected output statistics, rather than addressing the deficiencies of the physics in the models. However, climate models are also applied to the 19th and 20th century conditions to build simulations called "re-analysis". The re-analysis models are very similar conceptually to the IPCC models used for future extrapolations, with one important difference. These models use data assimilation of observed surface temperature and pressure records over the historical period. This means that the values of the climate variables computed by these models are updated to match as well as possible historical observations every single day. In effect, in this mode, the climate models are used to spatially interpolate the historical climate observations.

Observed data are sparser as one goes back in time, and during the world wars or other insurgencies, and hence the uncertainty and bias associated with the "re-analysis" reconstruction of the climate data fields varies as a function of time and space. Nevertheless, the multiple sources of "reanalysis" data that are available for daily rainfall, temperature and other variables, can be very useful for portfolio risk analysis, since

1. they provide a common period of global data coverage of 100 or more years (depending on which climate model is used);

2. as their temporal evolution is constrained by observations, they preserve the information on the phase of a climate oscillation across the world, thus providing information on the potential for spatial and temporal clustering of the frequency and intensity of hydroclimatic extremes;

3. they give the ability to assess how the hydroclimatic risk has evolved in the past in the best case scenario of an application of a climate model, thus providing a baseline against which future climate model-based projections could be scored.

Consequently, while the procedures we develop here could readily use future climate projections, in this paper we choose to develop examples that use long historical datasets so that we can reveal how potential changes in portfolio risk associated with rainfall extremes may have manifested over the past century or longer, thus providing a changing baseline for the risk that needs to be understood before undertaking an extrapolation to the future.

This paper represents the first attempt to develop an index for the exposure of a geographically diversified, global asset portfolio to the time-varying risk of climatic extremes using daily global rainfall datasets derived from climate reanalysis models. For the example presented here, we consider the mining sector, and extreme rainfall of specified duration as the risk factor. Once again, the analyses presented 
can be readily extended to consider the use of future climate projections based on the IPCC climate change scenarios. In this paper our emphasis is on exposing the potential for portfolio risk associated with climate risk, rather than the potential change of this risk as per these scenarios. The limited ability of these future scenarios to accurately inform extreme rainfall at this point of time, and the need to consider globally applicable uncertainty and bias correction methods to make these scenarios usable, leads us to consider that extension in a later paper.

The approach to the development of the index is described, followed by applications to selected sites and mining company portfolios. Extensions to other climate events, and to other applications, including simulation, value at risk analyses and portfolio optimization are finally discussed. The functioning of a web-based application has been developed to allow a user to conduct all the analyses described and illustrated in this paper. This web application is available upon request from the authors.

\section{Structuring a risk index for climate extremes}

The risk associated with an extreme rainfall event depends both on its probability of occurrence, and on the potential financial impact. This latter includes direct operational loss to the company, as well as potential liabilities from harm caused to others. Yet, direct causality between climate events and issues at the mine site may be hard to quantify, as parameters such as infrastructure design, mining methods, acid consumption or water management policies all play a role regarding the ways the impact of climate events are manifest. For example, from a hydrological perspective, as exemplified by Hailegeorgis and Alfredsen (2017) in the case of urban run-off, the relation between extreme precipitation events and extreme run-offs is complex, and its knowledge and calibration depends at the minimum on a detailed description of the infrastructure of the catchment, its moisture state, infiltration and exfiltration processes. Even when such information is known, lags in response can be hard to identify and uncertainties are important. Different approaches can be taken at a site level to further knowledge, for a given site including detailed numerical simulations or extensive data analyses of long time series of both precipitation, run-off and other site condition attributes (such as soil moisture). However, this requires data that are typically not available to people outside the mining company, and even for the company it may be difficult to estimate the extent of a projected loss from an extreme event.

Moreover, especially for rare or catastrophic events, it is difficult to develop a priori estimates of impacts in a global study, asset by asset, as they depend on the details of several site-specific attributes, such as local demography and development level, or details of actual construction and monitoring of infrastructure, information on which may not be easy to develop. A well-run company may conduct a risk-profiling exercise that identifies possible impacts contingent on certain types of events. An investor may indeed ask for such disclosure, covering the events of concern and their estimated annual probabilities of occurrence. However, if such information is not available, one needs a consistent approach for scoring potential impacts such that a fair index of exposure can be derived for a particular portfolio, whether it is composed of all mines in a particular geography, or a sector of mining, or belonging to a specific company. We develop such an approach here, and illustrate how the index derived can be used to

1. understand the potential clustering of impacts in a sequence of years;

2. assess the impact of climate trends, production and price cycles on the exposure index;

3. compare the portfolios held by two or more companies.

In the examples considered in this paper, we define extreme events in terms of the $T$-year return level (level exceeded by the annual maximum with a probability of $1 / T$ in any given year) based on available re-analysis datasets with at least 100 years of data. Two candidate extreme events are considered:

- a 1-day annual maximum extreme rainfall event with a 100 -year-return period, i.e. an average 0.01 probability of yearly occurrence $(p=0.01)$; and

- a 30-day annual maximum rainfall event with a 10-year return period, i.e. an average 0.1 probability of yearly occurrence $(p=0.1)$.

The 1-day extreme event is used as an example for rapid onset events that could induce spills and problems with tailings dams for a mine, while the 30-day event is used to consider events similar to ones that occurred in Queensland in 2010-2011, that are the consequence of persistent moderate to high-intensity rainfall events over a long period. A specific 30-day extreme event may or may not include a 1day extreme event, in a given year. A site can experience an event exceeding the target threshold several times during a given year as long as averaging windows (e.g. 30 days) do not overlap.

The motivation for the above choices is based in part on engineering design and regulatory practice, and in part on a desire to standardize exposure metrics. Depending on the type of mine or industrial installation, design guidelines for protection from flooding or extreme rainfall events typically refer to an event duration and an annual exceedance frequency corresponding to that duration. Thus, a holding pond for potentially contaminated run-off from rainfall on a site may be designed to hold the volume generated by a 30-day rainfall event with a 10 -year return period, while the main 
tailings dam may be designed to be able to capture the volume of water generated by a nominal 100-year, 1-day rainfall event. As previously stated, precipitation is only one aspect leading to leaks and infrastructure failures. The proposed benchmarking process could be modified, in various ways, for instance making use of the increased availability of high-resolution remote sensing (in the absence of better information), to derive more precise run-off and vulnerability information. This approach might in particular be suitable in building tools and proxies for site case studies. This is beyond the scope of this paper, but considered as an extension of the research. Keeping in mind the goals stated in points 13 , it is, for example, unclear that globally derived products regarding attributes such as soil moisture, evapotranspiration (e.g. Liu et al., 2012; Alemohammad et al., 2016), or even directly run-off (e.g. Hong et al., 2007; Fekete et al., 2002; Sheffield and Wood, 2007; Princeton Land Surface Hydrology Group, 2017) would help us highlight the fact that tackling uncertainty stemming from using short-term records is all-important, or to derive a better index, given the complexity of the sites considered. As was indicated in the introduction, given the short records typically used, there is considerable uncertainty as to the magnitude of the estimated 10- or 100-year rainfall events at a site. Since climate statistics are not stationary, any given 30-year period of data used for such inferences may not be representative of the next 30 years when the business is operating. Since there is no easy way to know a priori which specific period of record (e.g. 19401960 or 1960 to 1975) was used for the design of facilities at a particular mine or business site, it makes sense to refer the threshold to the longest period of record available to us, across all sites, and to then assess the space-time correlation and hence portfolio exposure to thresholds estimated across this entire period.

At each site, the nominal values corresponding to the extreme events of interest are computed from the NOAACIRES 20th century re-analysis V2c (also called 20CR) or the ECMWF ERA 20C (also called ERA-20C) re-analysis, which, to our knowledge, are the best precipitation datasets according to our criteria (global coverage, relatively high resolution and a long record) (Smith et al., 2014; Dee et al., 2014; Irving, 2016). The 20CR provides re-analysis rainfall data from 1 January 1851 to 31 December 2014 (NOAA ESRL, 2016) with a spatial resolution of $2^{\circ} \times 2^{\circ}$. ERA-20C dataset provides daily precipitation data from 1 January 1900 to 1 January 2011, with a spatial resolution of approximately $125 \mathrm{~km}$ by $125 \mathrm{~km}$ (NCAR UCAR, 2016). The 20CR data were downloaded from the NOAAESRL website (NOAA ESRL, 2016), while the ERA-20C data were downloaded from the NCAR-UCAR climate data website (NCAR UCAR, 2016).

As previously mentioned, since the spatial density of observations varies over time, the precision or accuracy of the estimates by these models also changes. Further, precipitation is highly variable in space, and hence a model with even a $1.25^{\circ}$ by $1.25^{\circ}$ spatial resolution is too coarse to provide useful information as to extreme rainfall. This is definitely an issue, and motivates our approach to look at the number of exceedances of a specified quantile at each location, rather than at the absolute magnitude of the rainfall generated by the model.

We expect that even the re-analysis models will be biased relative to at-site observations. However, noting that quantile mapping for bias correction of the IPCC models is seen as an effective strategy, we expect that using the quantiles of the model precipitation at a given location to define the threshold of exceedance for extreme rainfall may provide a reasonable internal self-consistency for the comparison of the relative exposure across different locations. Specifically, we assume that if the $p$ th quantile of model-based annual maximum precipitation is exceeded by $n$ days in a year at location $i$, and the $p$ th quantile of model-based annual maximum precipitation at location $j$, is exceeded by $m$ days at that location in a given year, then the relative magnitude of $n$ to $m$ exceedances at those two locations using the model-based data is a good measure on average of the relative exceedances of the corresponding $p$ th quantiles of observed annual maximum precipitation at the two sites. Recall that we are using model-based rainfall, since long records of observed rainfall at most of the sites (mines) of interest do not exist. While these long model-based records may not get the rainfall statistics at a given site exactly right, the persistence of extreme wet or extreme dry conditions across a region, or across a historical period is likely to be connected to features of the large-scale circulation of the atmosphere, which the models are expected to resolve quite well. Thus, for our purpose of exploring the spatial and temporal correlation of the risk of extreme rainfall event exceedance across many sites in a portfolio, and the relative risk of exposure of portfolio A to portfolio B, the approach chosen may be satisfactory. Uncertainty due to the model structure and to the data assimilation strategies can be explored by using multiple re-analysis models, and the ones used in this paper are the ones that, as of the date of publication, provide the longest re-analysis climate records.

\section{Approach}

Given the discussion in the previous section, we consider an event that triggers possible financial exposure of concern at a given site to be indexed to the exceedance of the $p$ th quantile of annual maximum rainfall of a duration of $d$ days. Depending on the investigator's interest, one can consider exposure relative to specified values of $p$ and $d$ at each site, the direct and indirect financial exposure to each such event at each site, and aggregate the exposure across sites, for each year of the historical record to provide a time series of the index of exposure for the portfolio of interest. Time series of the index can then be analysed for cyclical or secular trends, evidence of spatial clustering and the relative value at risk for 
portfolio A vs. portfolio B. The entire exercise could be repeated for different combinations of $p$ and $d$ to assess the kinds of events that may lead to the most differences in relative exposure. These ideas are developed formally below, and a web app that implements the analyses is available from the authors.

\subsection{Climate risk exposure}

We first choose a fixed level of exposure for a given climate event (extreme rainfall or drought) expressed in terms of its nominal annual probability of occurrence $p$ over a year. To explore the space-time structure of exceedances of this threshold, we first identify the exposure frequency of the event at a given asset, for each year of the historical record.

A first step is to identify the annual maximum of rainfall for duration $d$ at location $i$ from the climate dataset, for each year of the record. This time series of annual maxima is denoted as Precip $p_{i t}^{\max }$. The $p$ th quantile Precip $p_{i}^{\max , p}$ of Precip ${ }_{i t}^{\max }$ is then estimated as the empirical quantile or after fitting a generalized extreme-value (GEV) distribution (Katza et al., 2002) to Precip $p_{i t}^{\max }$.

Let us call $X_{j}$ the cumulative rainfall over $d$ days for a window starting on day $j \in[[1, J]]$ of the year (in practice, $J=365-d+1$ for a regular year, $J=366-d+1$ for a leap year). Then, under the assumption that the $\left\{X_{j}\right\}$ random variables are independent and identically distributed (i.i.d.), the extreme value theorem (Coles, 2001) tells us that calling $M_{n}=\max _{n}\left(X_{j}\right)$, if there exists sequences $\left(a_{n}\right)>0$ and $\left(b_{n}\right)$ such that $M_{n}^{*}=\frac{M_{n}-b_{n}}{a_{n}}$ converges to a non-degenerate cumulative distribution function (cdf) $G, G$ is of the GEV family, i.e. $G$ can be written as

$G(z ; \mu, \sigma, x i)=\exp -\left[1+\frac{\xi(z-\mu)}{\sigma}\right]^{-\frac{1}{\xi}}$

where $\mu$ is the location parameter, $\sigma>0$ is the scale parameter and $\xi$ is the scale parameter.

This distribution family can be divided into three subfamilies:

- for $\xi>0$, it is of the Fréchet type;

- for $\xi=0$, (limit of (2) when $\xi \rightarrow 0$ ) it is of the Gumbel type;

- for $\xi<0$, it is of the Weibull type.

This theorem is the counterpart of the extreme limit theorem for block maxima, and is in practice used in a similar way: to find an approximate distribution of $M_{n}$ for $n$ large enough (in practice, $n$ is fixed). The existence of the $\left(a_{n}\right)$ and $\left(b_{n}\right)$ sequences is assumed, and while these numbers are unknown, i.e., for $n$ large enough, $\operatorname{Pr}\left(M_{n}<z\right) \approx G\left(\frac{z-b_{n}}{a_{n}}\right)=G_{0}(z)$, where $G_{0}$ is a distribution of the same family, then the cdf of $M_{n}$ can be approximated (Coles, 2001). Obviously, critical assessment of the model fit needs to be performed, as with any statistical inference.
In practice, the cdf of $M_{n}$ is thus estimated by fitting a GEV to the Precip ${ }_{i t}^{\max }$ time series obtained from data. While the i.i.d. assumption does not hold in our case (moving window precipitation totals are obviously not independent), adjustments to the location and scale parameters can account for the time clustering (Katz, 2013); the process is still valid if the $\left\{X_{j}\right\}$ are of the same family (which takes care of the fact that the distribution parameters might vary depending, for instance, on seasonality).

The GEV model can account for non-stationarity by making $\mu, \sigma$ and/or $\xi$ functions of time $t$, although allowing $\xi$ to vary generally makes convergence difficult. Then, $\mu(t)$ will describe trends and cycles of the centre of the distribution, while $\sigma(t)$ will describe evolutions of the "size" of the deviations about $\mu$ (Katz, 2013). At a mine, study of the time series Precip ${ }_{i t}^{\max }$ through GEV can enable one to understand if and how exposure at different return periods has changed over time and what consequences this can have relative to the infrastructure design. Confidence intervals of such return levels can also be estimated. The parameters, $\mu(t)$ and $\sigma(t)$, can be estimated using maximum likelihood, and different forms of time variation (including constant for stationarity) of these parameters can be explored, and the best model selected using the BIC criterion (Katz, 2013).

Next we can develop a time series of physical exposure at each mine $i$, by estimating $n_{i,}^{p, d}$ as the number of events of duration $d$, which exceed the stationary threshold Precip $_{i}^{\max , p, d}$ at mine $i$ in year $t$, based on the long-run data (or for a mine operator, who has information on the original data used, the data period used for design). Then the statistic

$N_{t}(p, d)=\sum_{i} n_{i, t}(p, d)$

can be used to get insight into risk exposure at the portfolio level.

The degree of clustering of exposure across mines in the portfolio, and whether there are temporal trends or cycles in such exposure can then be investigated using $N_{t}(p)$. Clustering can be assessed by comparing the probability distribution of $N_{t}(p)$ against what would be expected under independence of occurrence of extremes at each mine, and trends can be assessed via standard methods of trend and cyclical analysis.

\subsection{From climate exposure to financial risk}

In the financial industry, a common measure of risk is the value-at-risk or VaRq. It is defined as the potential loss (incurred by a given risk factor) over a certain time period that will not be exceeded with a given confidence level $q$ (Webby et al., 2007; Yamout et al., 2006; Adriaens et al., 2014). A conditional value-at-risk (CVaRq) is defined as the expected value of the loss in case the $\mathrm{VaRq}$ is exceeded. More precisely, using the definitions from Sarykalin et al. (2008), the VaR of $X$ with confidence level $\alpha$ is 
$\operatorname{VaR} \alpha(X)=\min \left\{z \mid F_{X}(z) \geq \alpha\right\}$. The CVaR of $\mathrm{X}$ with confidence level $\alpha$ is defined through a generalized tail distribution, as the expected shortfall if the loss event of concern occurs:

$\operatorname{CVaR}_{\alpha}(X)=\int_{-\infty}^{+\infty} z d F_{x}^{\alpha}(z)$,

where $F_{x}^{\alpha}(z)=0$ when $z<\operatorname{VaR} \alpha(X)$, and $F_{x}^{\alpha}(z)=\frac{F_{X}(z)-\alpha}{1 \alpha}$ if $z \geq \operatorname{VaR} \alpha(X)$.

We take an approach consistent with these ideas, while recognizing that it may not be easy to estimate the direct loss associated with different levels of events at each mining site.

Our strategy is to use a weighting of the $n_{i, t}(p)$ time series to be able to compare portfolios to each other, rather than estimating actual VaRs, based on mine by mine potential loss associated with the threshold event. For each mine site $i$, a potential loss $L_{i}(p, d)$ is associated with the event with return period $p$. We assume that $L_{i}(p)$ can be decomposed as

$L_{i}(p, d)=C(p, d) V_{i}+D(p, d) F_{i}$

where

- $C(p, d$ and $D(p, d)$ are constants associated with the rarity and duration of the event, that apply to direct loss and external loss respectively;

$-V_{i}$ is a measure of the financial value of the mine;

- $F_{i}$ is a measure of the potential value of impacts on society external to the mine, that the mine owner is liable for.

$V_{i}$ can for instance be the production rate of the mine, some multiple $C(p, d)$ of which may be lost due to disruption, for an event with a probability of occurrence $p$ in a given year. Alternately, $V_{i}$ could be the estimated net asset value (NAV) of the mine, which may be relevant as a measure of the scale of the asset at risk. Production loss could be used in the context of an event expected to incur mine flooding, difficulty of access, or cut in production due to drought. In such a case, $L_{i}(p, d)$ would represent the value of the potential loss of production due to disruption, and one would expect that as $\mathrm{p}$ decreases (the event is more extreme), $C(p, d)$ increases. Similarly, NAV could be used to reflect potential closure of the mine, or a long-term suspension of operations due to a catastrophic event. The probability $p$ considered for an index that uses this measure for defining $V_{i}$ would logically be lower than the ones used for a production-based index.

Correspondingly, one can develop arguments for $D(p$, $d$ ) and $F_{i}$ considering the population or ecosystems that are likely to be affected as a consequence of the failure of systems at a mine in the event of extreme rainfall. This could include environmental impacts, health impacts, loss of water services to a community and/or the financial impact from mine closure. Available satellite remote sensing and geospatial data bases provide information on hydrologic networks, population density, economic activity and ecological attributes that could be identified downstream of each mine, and used to parameterize $F_{i}$. In reality, it is difficult to develop estimates for $D(p, d), C(p, d)$ and $F_{i}$ without insider information. Therefore, in the examples developed in this paper, we take $C(p, d)$ to be 1 , and $D(p, d)$ to be 0 .

Effectively, we assume that there is a valuation associated with the mine as well as with the potential area of external impact, and that for an extreme event of a specified rarity (probability of occurrence), across sites, the loss is proportional to that valuation. As an example, if a 100-year event $(p=0.01)$ were to occur at two mines, with the market apportioning USD 10 million to one asset and USD 100 million to another asset, in the absence of other information, we are assuming that the financial impact is directly proportional to the relative valuations attributed by the market to each asset. This implies that for a 100 -year event that results in permanent mine closure (for example), the resulting impact on the company's valuation as a result of the event at the second mine would be 10 times greater than the same event at the first. While this is unlikely to be an exact measure of financial impact, it represents a relative measure of exposure, and hence provides a basis for developing a comparable index across a portfolio. Where detailed information on the potential asset-level loss probability distribution and the direct resulting financial impact is available, it would obviously be better to use it directly. Varying $p$ allows for the development of a probabilistic risk profile across a portfolio. One can see that for a given $p$, the contribution to the expected value at risk can be readily evaluated, under assumptions of a stationary climate, as $p L_{i}(p, d)$.

We can then define portfolio level financial exposure as

$S_{t}(p, d)=\sum_{i} L_{i}(p, d) n_{i, t}(p, d)$,

which can be reframed as

$S_{i}^{\prime}(p, d)=\sum_{i} V_{i} n_{i, t}(p, d)$

since $C(p)$ is assumed to be a constant across all assets, and for now we assume that we are only considering direct impacts to the mine. Normalizing by the portfolio valuation, we define

$R_{t}(p, d)=\frac{S_{t}^{\prime}(p, d)}{\sum_{i} V_{i}}$,

which provides a metric for the relative volatility or risk exposure of different portfolios (companies or economic sectors), normalized by their valuation. For instance, two different companies can be compared in terms of the quantiles and trends of their respective $R_{t}(p, d)$. Varying $p$ also enables the exploration of the variations in tail risks of a given portfolio. 
For a specified annual probability of exceedance $p$, considered to be the design level for infrastructure at the mine, the $q$ th quantile, $S_{q}^{\prime}(p, d)$ of $S_{t}^{\prime}(p, d)$ can be considered to be a measure of the VaRq for a mining company, and the corresponding $q$ th quantile $R_{q}(p, d)$ of $R_{t}(p, d)$ provides a scaled measure that allows for a comparison of the VaRq exposure of each company as a fraction of their total production or total portfolio value.

Finally, we can define a measure similar to CVaRq for the potential expected loss in case an event with a probability lower than $p$ occurs with a probability $(1-q)$ of the time as

$\mathrm{CVR}_{q}(p, d)=\frac{1}{1-q} \int_{R_{q}(p, d)}^{R_{m}(p, d)} R_{t}(p, d) f\left(R_{t}(p, d)\right) d R_{t}(p, d)$.

This is numerically evaluated as

$$
\begin{gathered}
\operatorname{CVR}_{q}(p, d)=\frac{1}{(1-q)(m+1)}\left\{\frac{R_{q}(p, d)+R_{m}(p, d)}{2}\right. \\
\left.+\sum_{k=q+1}^{m-1} R_{k}(p, d)\right\},
\end{gathered}
$$

where $m$ is the number of years in the record, and $R_{k}(p, d)$ represents the $k$ th ranked value of the series $R_{t}(p, d)$, such that $R_{q}(p, d)$ corresponds to the $q$ th quantile of $R_{t}(p, d)$.

Similarly, one can define

$\operatorname{CVS}_{q}^{\prime}(p, d)=\frac{1}{1-q} \int_{S_{q}^{\prime}(p, d)}^{S_{m}^{\prime}(p, d)} S_{t}^{\prime}(p, d) f\left(S_{t}^{\prime}(p, d)\right) d S_{t}^{\prime}(p, d)$.

Further, such a procedure can be used to generate inputs for real-option analysis models to inform the value-at-risk (Blanchet and Dolan, 2016). For different values of $p$, distributions of $n_{i, t}^{p}, N_{t}(p, d), S_{t}^{\prime}(p, d)$ or $R_{t}(p, d)$, can be used to simulate extreme event impacts.

\section{Example applications - frequency of events at the mine level}

We start with an example for the analysis of the Precip $\max _{i t}$ time series for a given site using GEV distribution for threshold selection. Consider again the Highland Valley openpit copper mine in British Columbia. Let us consider a 30 -day event with a return period of 10 years. Using the 20CR dataset, we develop the yearly maximum 30-day precipitation time series Precip $\max _{i t}$. The eXtremes package in $\mathrm{R}$ (Gilleland and Katz, 2016) was used to estimate an appropriate parametric model in the GEV framework associated with this annual maximum time series. For the stationary assumption, the 10-year event is estimated as $126.2 \mathrm{~mm}$ consistent with the empirical quantile of $126.2 \mathrm{~m}$, with a $95 \%$ confidence interval of $[122.21 ; 131.19 \mathrm{~mm}]$.

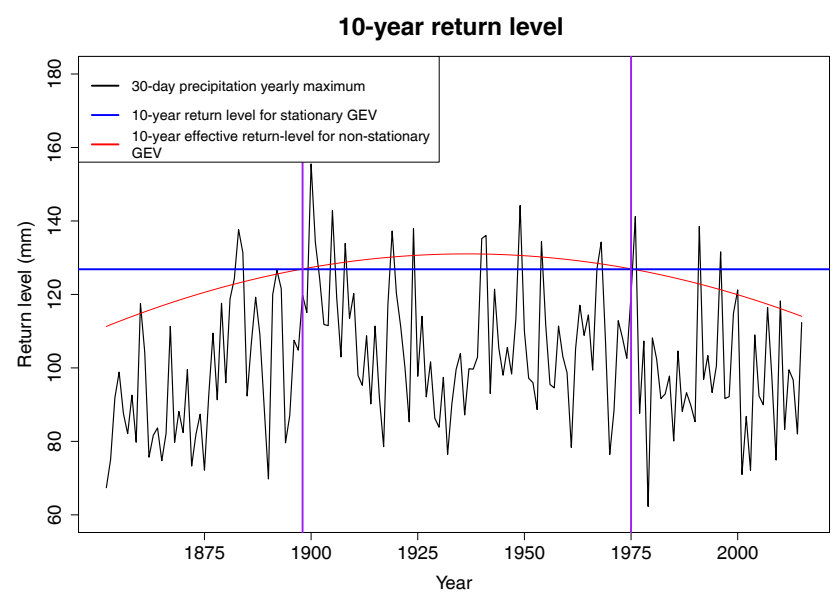

Figure 2. Effective 10-year-return level according to the nonstationary GEV distribution for the Highland Valley mine.

We considered polynomial models in time of the order of 0 to 4 for both the location and scale parameters of the GEV distribution, leading to 24 models to be tested, including the stationary model. The best model based on the BIC criterion is the quadratic model for the location parameter and a constant for the scale:

$\mu(t)=74+0.47 t-0.0039 t^{2} ; \quad \sigma=3.4 ; \quad \xi=-0.26$.

A likelihood-ratio test between the stationary model and this model leads to a $p$ value of $4.85 \times 10^{-5}$, thus enabling us reject the null-hypothesis of no trend. Standard diagnostic tests support the applicability of the non-stationary GEV model. The return-level plot on Fig. 2 shows the effective return-level plot of a 10-year, 30-day rainfall event for the non-stationary model in blue under stationarity assumption, and for the model selected thanks to BIC in red. A nonparametric trend function, as illustrated in Fig. 1 could potentially reveal additional structure. If a more detailed characterization of the decadal variations in the return level were of interest at this site, the use of a spline basis function for the trend in the location parameter may be appropriate, as shown by Bocci et al. (2012), Padoan and Wand (2008), Nasri et al. (2013) and Yousfi and El Adlouni (2016).

\section{Example applications - portfolio level}

In this paragraph, we provide three examples at the portfolio level across a set of mining companies for which we have information on asset locations and $V_{i}$.

1. The purpose of the first example is to explore whether spatial and temporal correlation in the frequency of climate extremes leads to portfolio tail risk that may (a) be substantially greater than expected from treating each asset as an independent exposure or (b) have systematic increasing or decreasing trends or persistence. For this 
case, we study the number of events affecting a given portfolios of mines via the corresponding $N_{t}(p d)$.

2. The second application highlights how different choices for $V_{i}$ can be used to provide insight into financial exposure. Two weighting procedures are considered. One uses 2015 production and 2015 average commodity prices to attribute a value to each mine, and the other uses NAV from broker reports. In the first case, for mine $i$,

$V_{i}=\sum_{c} P_{c} Q_{i, c}$,

where $P_{c}$ is the average 2015 unit price of commodity, $c$ obtained from Word Bank (2016) and $Q_{i, c}$ is the quantity of this commodity produced by mine $i$ in 2015 .

In the second case, for mine $i$,

$V_{i}=\mathrm{NAV}_{i}$,

where $\mathrm{NAV}_{i}$ is the NAV attributed to site $i$ in the broker report chosen.

3. The third example highlights how the $N_{t}(p d), S_{t}^{\prime} t(p$, $d)$ and $R_{t}(p d)$ time series can be used to compare the tail risk that results from clustering for two portfolio of mines, depending on how the assets are valued or grouped.

Data on different mining companies were gathered for these applications. The details of this data are provided in Appendix A (Figs. A1-A6, Tables A1-A6).

For the first application, we build portfolios of producing mining assets for four companies (BHP Billiton, 2016; Rio Tinto, 2016; Barrick Gold Corporation, 2016; Newmont Mining Corporation, 2016) using their annual reports. Using BHP and Rio Tinto enables us to test our method on two large portfolios, to measure whether or not their portfolios are diversified with respect to the risk of rainfall extremes. Barrick Gold and Newmont Mining, two of the main gold miners, are chosen because they are similar in terms of size and business, and can be also used to illustrate applications (2) and (3). In this case, a mining asset refers to a unique physical site. The dataset includes mines that may be listed as "on care and maintenance" but excludes undeveloped projects. Generally speaking, mining portfolios were disaggregated based on public disclosure using our best judgement on what constitutes an individual asset, for each mining company, and the share of ownership in jointly owned assets by multiple companies.

For the second application, the portfolios of mines defined for Barrick Gold and Newmont Mining for the first application are used first. These two companies produce mainly gold and copper, and the reported production of these two commodities is used to value each mine as indicated in Eq. (5). Then, we consider NAV weighting for Barrick Gold and Newmont, obtained from broker reports (TD Securities, 2016a, b). These portfolios of mining sites are different from the ones defined for the first application; i.e. they are composed of the assets valued in the broker reports used to obtain NAV valuations (whether they are undeveloped projects, producing assets, or even closed mines).

In total, for the first two examples, six different portfolios of mines are considered (one for BHP and Rio Tinto, and two for Barrick and Newmont). For the second application, Barrick Gold and Newmont Corporation are compared using the different weighting methods proposed $\left(V_{i}=\sum_{c} P_{c} Q_{i, c}\right.$, $\left.V_{i}=\mathrm{NAV}_{i}\right)$.

For the last application, portfolios of mine sites of $15 \mathrm{com}$ panies for which we have asset-level NAV valuations from TD Securities broker reports are used (including the ones for Barrick Gold and Newmont Corporation already introduced for the NAV weighing example in the second application) (TD Securities, 2016a-o).

\subsection{Frequency of events across a portfolio, $N_{t}(p, d)$}

We consider a 1-day rainfall event with a 100 -year return level and a 30-day rainfall event with a 10-year return level. For each of the aforementioned companies, we compute the $N_{t}(p, d)$ corresponding to the portfolios of producing mining assets, using both the 20CR and the ERA-20C climate datasets.

\subsubsection{Trends and clustering in time}

From studying the $N_{t}(p, d)$ for the four mining companies we find that

- statistically significant trends for increasing frequency are observed in most of the cases, in particular when using the longer 20CR climate dataset;

- there is a cyclical behaviour regarding the number of exceedances of the thresholds defined.

In nearly all cases analysed (independent of the climate dataset used), we observe a cyclical behaviour in the number of exceedances. Figure 3 shows the location of the mining assets for Rio Tinto. Figure 4 provides the time series of the yearly number of 30-day extreme events across this portfolio that exceed the 10-year return level at each site computed using the 20CR climate dataset. For this case, we observe a high number of events for the periods 1940-1950, 19801990 and 1995-2005, while the 1950-1980 period is relatively quiet. Thus, infrastructure designed and constructed using the 1940-1950 record as a basis might have given this company's executives a sense of security during the 1950 1980 period, while the following years might have appeared as a period of high exposure. People tend to weight recent history more than the past, which would yield cyclical investment and attention to risk management for such a company. 


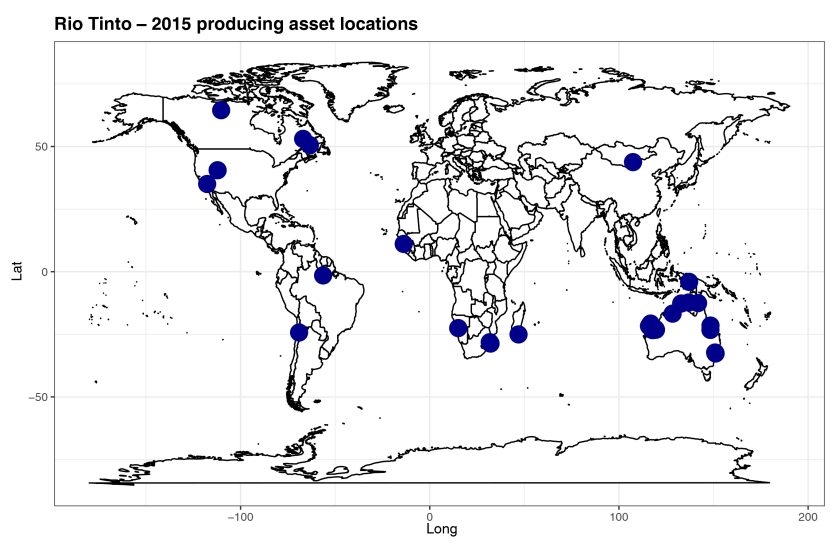

Figure 3. Locations of productive Rio Tinto mining assets at the end of 2015 (some assets overlap on the map).

Similar results for other companies are shown in Appendix B (Fig. B1).

Significance of the trends for each of the $N_{t}(p, d)$ time series estimated was assessed using the Mann-Kendall test (Helsel and Hirsch, 2002) for monotonic trend. Results are provided in Appendix B (Tables B1-B2). For the 100-year, 1-day rainfall event, the number of events exceeding the design level at the portfolio level demonstrates statistically significant (at the $5 \%$ level) trends for all companies using the 20CR data, and for Barrick Gold and Newmont using the ERA-20C data. However, the trends computed are null, which is due to the fact that a Sen Slope is computed as the median of the slopes between all the points in a dataset, and most of the years then correspond to zero values. For the 10year, 30-day event, the portfolio counts exhibit statistically significant upward trends for all mining companies when using the 164-year-long 20CR data, and only for Rio Tinto when using the 111-year-long ERA-20C data. Thus, there is evidence for an increasing frequency of portfolio level exposure for both the more catastrophic short duration event and the long duration, more moderate event that we hypothesize is related to persistent production disruption.

\subsubsection{Clustering in space and time}

Our key finding is that for all cases, the number of exceedances for each mining portfolio in many years is substantially higher than what would be expected by chance. There is evidence of very fat tails for the portfolio risk.

Representative results are discussed here, with all results presented in Appendix C. From Fig. 4, it is interesting to note that there were 36 exceedances of a 10-year, 30-day rainfall event were experienced in a portfolio of 40 Rio Tinto assets in 1981. We emphasize that a single asset can potentially have multiple, distinct 30 -day periods that can experience an exceedance of the 10-year event at the site in a given year. Thus, in the worst years, the number of exceedances may exceed the number of sites in the portfolio. For exam- ple, in 1981, several Rio Tinto assets were hit twice. These included the iron ore mines of the portfolio located close to each other in the Pilbara region of Australia. However, hits happened in various parts of the world, and 22 different sites were hit (their geographic distribution is showed on Fig. 5).

Since on average one would expect four such exceedances $(p=0.1 \times 40)$ in a year, 36 hits is truly a remarkable number, suggesting a very fat tail exposure for the portfolio compared to what could be expected by chance. Practically, if each such event were to lead to even a $12.5 \%$ production loss (based on the 1-month duration of the event and 0.5 months to restore full production) at a mine on average, then the portfolio would suffer a production loss of $35 / 40 \times 12.5=11 \%$ for the year, compared to $\sim 1.2 \%$ if there was no clustering across mines and in time. The financial impact for the mining company would depend on the fixed costs that would need to be incurred irrespective of production (in the event of a production stoppage) as well as the foregone revenue during the production stoppage. We note that there are other years in which very high counts are also recorded. Consequently, it is useful to formally test whether or not the number of exceedances across sites could occur if the climate risk exposure across sites were random and independent.

For this check, we compare the empirical cdf of the data, $F\left(N_{t}(p, d)\right)$ with the cdf that one may expect if the underlying process that generated $N_{t}(p, d)$ were an independent and identically distributed (i.i.d.) process, across the sites in the portfolio. As we have defined extreme events in terms of an yearly probability of occurrence $p$, at each site, the theoretical process can be assumed to be a Poisson process with $\lambda=p$. Therefore, for $m$ sites, under the assumption of an i.i.d process, the theoretical distribution would be one of a Poisson process with $\lambda=m p$. For the Rio Tinto portfolio, the number of exceedances with $\lambda=4$ would be $(9,11,13)$ for probabilities of $(0.01,0.001,0.0001)$ respectively. Thus, under the independence hypothesis there is a near-null probability of 36 exceedances in a year, and in 15 out of 164 years, the number of exceedances is greater than 13, suggesting a very high incidence of clustering indeed. From Fig. 6, we note that for the 100-year, 1-day rainfall event, depending on the climate dataset used, the number of portfolio events of concern at the 99th quantile is 5 to 6 times what may be expected by chance for BHP Billiton, and 2 to 3 times what is expected by chance for other companies and quantiles. Similar results for the 10-year, 30-day event are presented in Appendix $\mathrm{C}$.

To the extent the market tends to look at each mine as an independent profit centre, generating value as a standalone entity and with a subset of risks that are independent to the other mines that it owns (and others such as commodity risk which are present across the entire portfolio), our analysis demonstrates that the exposure to extreme rainfall events needs to be looked at across assets; clustering is a significant issue and high-impact events at the portfolio level may have a 


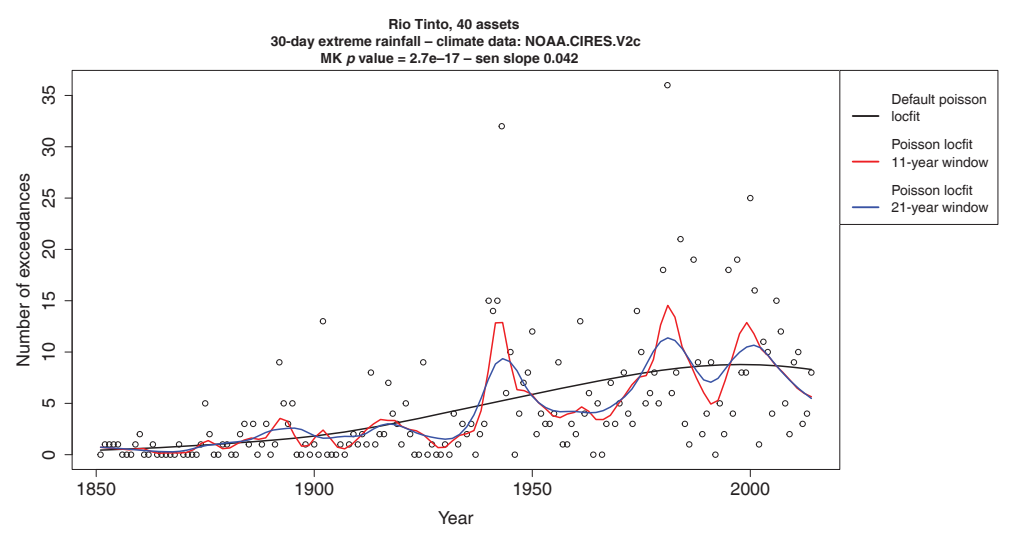

Figure 4. Time series $N_{t}(p, d)$ of the yearly number of 30-day extreme rainfall events exceeding the 10-year return level for the Rio Tinto portfolio computed using the 20CR dataset, using 3 windows $(11,21$, and 114 years) to illustrate different aspects of long-term variability.

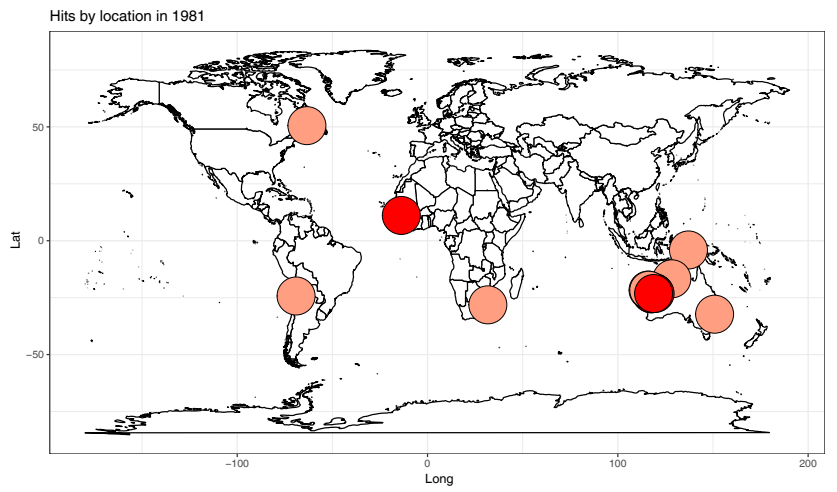

Figure 5. Hits by location for the Rio Tinto portfolio in 1981 for a 30-day, 10-year rainfall event according to the 20CR dataset (dark red corresponds to two exceedances, light red to one).

much higher probability of occurrence than anticipated under the usual analytical mindset.

\subsection{Extreme events and indexing of potential financial loss at the portfolio level}

In this section, we explore how the financial exposure of mining companies may be manifest for the two types of rainfall events considered at the portfolio scale, by weighting the event occurrence with an appropriate financial variable. We focus on Barrick Gold and Newmont Corporations, two major gold miners, because these two companies are similar in terms of their core business, their diversity in geographic distribution of asset locations, and their revenues. We consider both a 1-day extreme rainfall event with a 100-year return level, and a 30-day extreme rainfall event with a 10-year return level. All the computations in this section were performed using time series built with the 20CR dataset, as it has a longer record, with 164 years of data.
We use two weighting methods:

- one that values each mine using an estimate of its recent annual production value

- one that values each mine according to a recent NAV indicated in a broker report.

The method using production value is a measure of shorterterm impact of the events, while the NAV method may be used to measure more catastrophic losses.

\subsubsection{Weighting with production}

First, we develop an index using annual production data at the mine level reported in Barrick Gold Corporation (2016) and Newmont Mining Corporation (2016). We focus on the two main commodities reported by these two companies: copper and gold. We associate to each mine its production multiplied by the average 2015 price of the corresponding commodity, therefore obtaining an estimate of the mine's 2015 revenue. Commodity prices (in nominal dollars) were taken from Word Bank (2016). While the total sales revenue mentioned in the 2015 annual reports of Barrick Gold and Newmont amount to USD 9029 million and 7729 million respectively, the estimated values based on this indexing procedure are USD 7738 million and 6240 million, which have approximately the same ratio.

Using this weighting method, we then analyse the tail exposure through the weighted time series $R_{t}(p, d)$. Figure 7 shows the annual exceedance probability of exposure given by the $R_{t}(p, d)$ obtained for the Barrick Gold and Newmont Corporation portfolios both the 1-year, 1-day event and the 10-year, 30-day extreme event. Note for instance that for the 30-day event, for Barrick Gold, over 99\% (46\%) of the company's total production value is exposed with a probability of $1 \%(5 \%)$ per year, while for Newmont the corresponding numbers are 90 and $58 \%$ (recall that the total can theoretically go beyond $100 \%$ has multiple hits can 


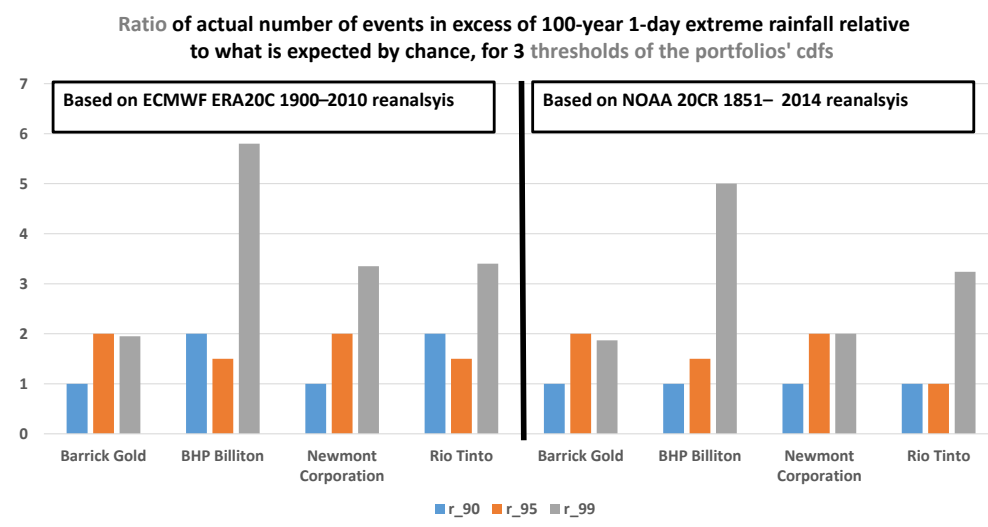

Figure 6. Ratio of actual number of events in excess of at-site, 100-year, 1-day extreme rainfall for a portfolio relative to what is expected by chance based on the Poisson distribution, for three thresholds of the portfolio cdf.

concern one asset in a given year). If we consider a $12.5 \%$ disruption in production due to each such an event, then for Barrick and Newmont, the annual financial impact could be as much as USD $9 \times 0.125 \times 0.99=$ USD 1.1 billion, and USD $7.7 \times 0.125 \times 0.9=$ USD 0.87 billion with a $1 \%$ chance in a given year.

\subsubsection{Weighting with net asset values}

For this example, we chose two reports from TD Securities written a few days apart: TD Securities (2016a, b). In the following, a mine or a project is included as long as it appears in the report. This leads to 19 sites mentioned for Barrick Gold, and 12 for Newmont Corporation.

In a similar analysis to Sect. 4.2.1, note (see Fig. 8) for instance that for a 1-day event, for Barrick Gold, over $29 \%(7 \%)$ of the company's total production value is exposed with a probability of $1 \%(5 \%)$ per year, while for Newmont the corresponding numbers are 33 and $9 \%$. If we consider a $10 \%$ destruction of value (which is likely a low number) due to each such event, then for Barrick and Newmont, the annual financial impact could be as much as USD $9 \times 0.10 \times 0.29=$ USD 0.26 billion, and USD $7.7 \times 0.10 \times 0.33=$ USD 0.25 billion with a $1 \%$ chance in a given year.

\subsection{Company comparison}

We obtained asset-level valuation for 15 companies from TD securities, performed around the same time (winterspring 2016) and present here the rankings ensuing from applying the method described using time series built using the 20CR climate data. We consider the 100-year, 1-day extreme rainfall with a 100-year return level, with NAV weighting and choose a portfolio tail-exposure level of $q=0.95$ to exemplify how the $S_{q}^{\prime}$ (Table 1 ), $R_{q}$ (Table 2) and corresponding $\mathrm{CV}_{q}$ measures that are similar to $\mathrm{VAR}_{q}$ or $\mathrm{CVAR}_{q}$ can be used to compare these companies exposure. A user may want to vary $q$, using our web app to develop customized results (in the following, a higher rank means a higher potential exposition).

A first thing that can be noted is that in our examples, ranks vary significantly depending on the use of the $S_{t}^{\prime}(p$, $d)$ or $R_{t}(p, d)$. For instance, Barrick Gold and Newmont Corporation both appear amongst the most exposed companies (for both measures) when using $S_{t}^{\prime}(p, d)$, but much less when using $R_{t}(p, d)$, which makes sense as these two companies are rather large, but have a relatively diverse portfolio in terms of their geographical locations and climate exposure. A second observation is that the two indices (the one akin to VaR and the one akin to CVaR) do yield some differences in ranking, in particular for First Quantum Mineral. This company has relatively few mines (nine assets are valued in the broker report), with a relatively important geographical variability; some of these assets are small, while a couple of projects are fairly large and with very high valuation. This explains the discrepancy between the two indices. Finally, for cases in which the number of hits recorded is too low overall (e.g. Hudbay), our indices (and in particular the quantile one) might not be usable when working with empirical data.

\section{Summary and discussion}

Global water risk including scarcity, flooding, pollution and anthropogenic climate change is of increasing concern to investors, companies, regulators and governments worldwide. Despite the recognition that these factors exist, an approach towards portfolio risk assessment that accounts for the geographical distribution of assets in a portfolio, and the associated exposure to climate extremes has not emerged. Such an assessment is of growing interest in particular to long-term investors, who are the owners of these multi-national businesses and currently lack a concrete methodology to compare 

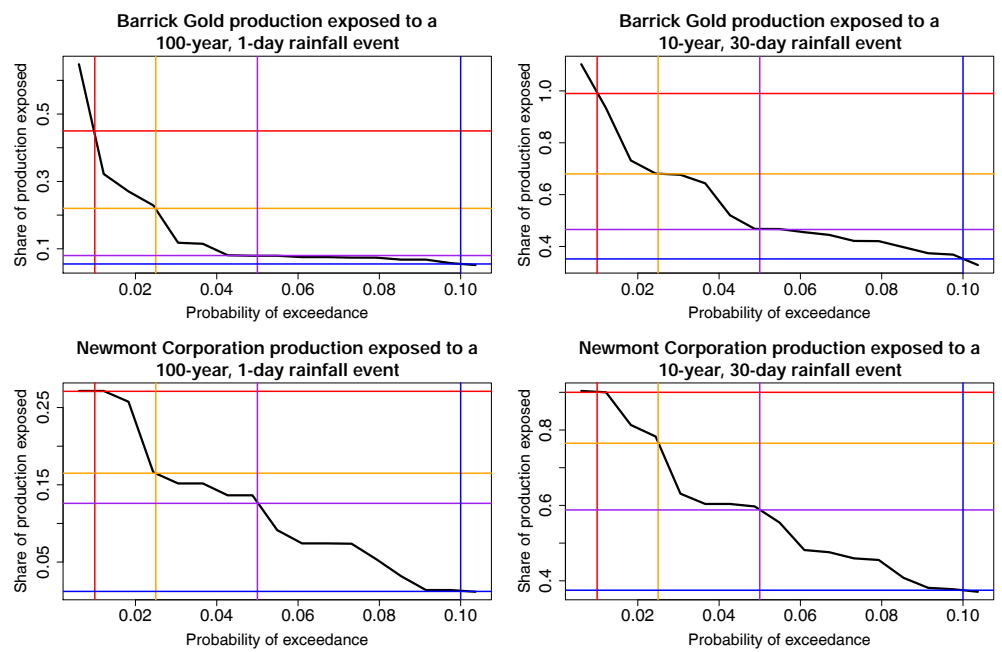

Figure 7. Fraction of company production value exposed, as a function of annual exceedance probability for 100-year, 1-day and 10-year, 30-day events for Barrick Gold and Newmont based on the 20CR data.
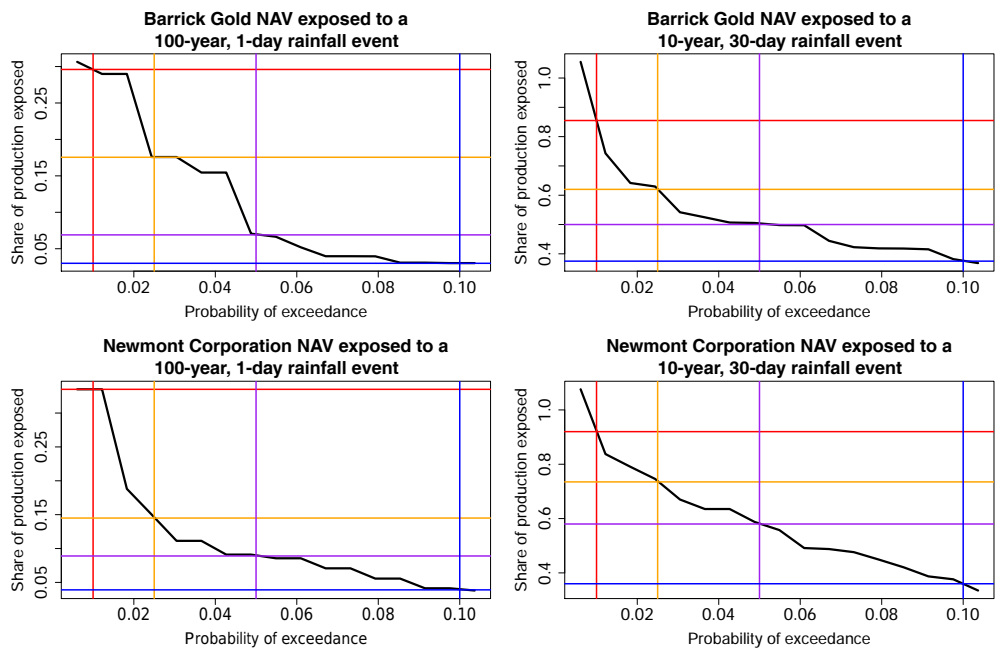

Figure 8. Fraction of company value exposed, as a function of annual exceedance probability for 100-year, 1-day and 10-year, 30-day events for Barrick Gold and Newmont based on the 20CR data.

the relative risks associated with different companies comprising their investment portfolios.

This paper represents perhaps the first effort to address this gap. A simple index that can be obtained through weighting by appropriate financial measures of exposure was developed and illustrated. Our hypothesis was that businesses with agricultural supply chains, and the mining industry, were likely to have significant spatio-temporal correlation in their assetlevel exposure that could potentially lead to a fat tailed exposure at the portfolio level. The mining industry presented an opportunity for exploring such risks, given that the locations of mines, and various attributes related to the mines can be readily ascertained from publicly available information. Further, as engineered enterprises, it is common for mining companies to use risk-based design criteria for structures in- tended to mitigate the impact of extreme rainfall-related hazards at each mine.

While the short climate records typically used to estimate the design parameters for such structures translate into considerable uncertainty as to the appropriate level of design, the fact that a structure is being designed with a nominal annual probability of failure $p$ directly translates into an estimate of the residual risk that the enterprise is exposed to. Consequently, if long climate records or projections are available, then one can estimate how the residual risk or exposure at each site varies with time, and also if multiple such events could happen in the same year across a portfolio of mines. This observation opens up the possibility of exploring the spatial and temporal clustering of risk exposure and its manifestation at the portfolio level, whether the portfolio 
Table 1. Ranking of 15 companies based on $S_{0.95}^{\prime}(0.01,1)$ and $\operatorname{CVS}_{0.95}^{\prime}(0.01,1)$ measures for a 1-day rainfall event, obtained using the 20CR dataset and mine valuation obtained from broker reports from TD Securities.

\begin{tabular}{|c|c|c|c|c|}
\hline Company & $\begin{array}{r}S_{0.95}^{\prime} \\
(0.01,1) \\
(\mathrm{USD} \mathrm{m})\end{array}$ & $\begin{array}{r}\text { Rank } S_{0.95}^{\prime} \\
\quad(0.01,1)\end{array}$ & $\begin{array}{l}\mathrm{CVS}_{0.95}^{\prime} \\
(0.01,1) \\
(\mathrm{USD} \mathrm{m})\end{array}$ & $\begin{array}{r}\text { Rank } \\
\text { CVS }_{0.95}^{\prime} \\
(0.01,1)\end{array}$ \\
\hline Agnico Eagle & 272 & 8 & $8.05 \times 10^{2}$ & 8 \\
\hline B2Gold & 204.3 & 10 & $4.14 \times 10^{2}$ & 13 \\
\hline Barrick Gold & 974.15 & 2 & $2.63 \times 10^{3}$ & 2 \\
\hline Capstone Mining & 0 & 14.5 & $1.10 \times 10^{2}$ & 15 \\
\hline Eldorado & 374.66 & 7 & $7.25 \times 10^{2}$ & 10 \\
\hline First Quantum Mineral & 136.595 & 12 & $3.65 \times 10^{3}$ & 1 \\
\hline Franco Nevada & 452.015 & 6 & $7.66 \times 10^{2}$ & 9 \\
\hline Goldcorp & 669.6 & 4 & $1.42 \times 10^{3}$ & 4 \\
\hline Hudbay & 0 & 14.5 & $5.58 \times 10^{2}$ & 11 \\
\hline Iamgold & 25.84 & 13 & $2.67 \times 10^{2}$ & 14 \\
\hline Kinross & 578.5 & 5 & $1.38 \times 10^{3}$ & 5 \\
\hline Lundin Mining & 233 & 9 & $1.24 \times 10^{3}$ & 7 \\
\hline New Gold & 141.4 & 11 & $4.66 \times 10^{2}$ & 12 \\
\hline Newmont & 1011 & 1 & $1.72 \times 10^{3}$ & 3 \\
\hline Teck Resources & 832 & 3 & $1.25 \times 10^{3}$ & 6 \\
\hline
\end{tabular}

Table 2. Ranking of 15 companies based on $R_{0.95}(0.01,1)$ and $\operatorname{CVR}_{0.95}(0.01,1)$ measures for a 1-day rainfall event, obtained using the 20CR dataset and mine valuation obtained from broker reports from TD Securities.

\begin{tabular}{lcrcr}
\hline Company & $\begin{array}{c}R_{0.95} \\
(0.01,1)\end{array}$ & $\begin{array}{r}\text { Rank } \\
R_{0.95} \\
(0.01,1)\end{array}$ & $\begin{array}{c}\mathrm{CVR}_{0.95} \\
(0.01,1)\end{array}$ & $\begin{array}{r}\text { Rank } \\
\mathrm{CVR}_{0.95} \\
(0.01,1)\end{array}$ \\
\hline Agnico Eagle & $5.67 \times 10^{-2}$ & 10 & $1.68 \times 10^{-1}$ & 12 \\
B2Gold & $8.95 \times 10^{-2}$ & 3 & $1.81 \times 10^{-1}$ & 9 \\
Barrick Gold & $6.43 \times 10^{-2}$ & 9 & $1.73 \times 10^{-1}$ & 11 \\
Capstone Mining & $0.00 \times 10^{-2}$ & 14.5 & $1.84 \times 10^{-2}$ & 7 \\
Eldorado & $8.95 \times 10^{-2}$ & 4 & $1.73 \times 10^{-1}$ & 10 \\
First Quantum Mineral & $1.43 \times 10^{-2}$ & 13 & $3.81 \times 10^{-1}$ & 1 \\
Franco Nevada & $7.54 \times 10^{-2}$ & 6 & $1.28 \times 10^{-1}$ & 15 \\
Goldcorp & $6.91 \times 10^{-2}$ & 7 & $1.47 \times 10^{-1}$ & 13 \\
Hudbay & $0.00 \times 10$ & 14.5 & $2.09 \times 10^{-1}$ & 6 \\
Iamgold & 12 & $2.29 \times 10^{-1}$ & 4 \\
Kinross & $2.22 \times 10^{-2}$ & 2 & $2.25 \times 10^{-1}$ & 5 \\
Lundin Mining & $9.41 \times 10^{-2}$ & 8 & $3.48 \times 10^{-1}$ & 2 \\
New Gold & $6.54 \times 10^{-2}$ & 11 & $1.83 \times 10^{-1}$ & 8 \\
Newmont & $5.55 \times 10^{-2}$ & 5 & $1.45 \times 10^{-1}$ & 14 \\
Teck Resources & $8.56 \times 10^{-2}$ & 1 & $2.55 \times 10^{-1}$ & 3 \\
\hline
\end{tabular}

is composed of multiple companies or a single company; is concentrated in a particular sector of mining, e.g. copper, or is diversified; and whether it is largely based in one country or is geographically diversified. An investor or a company can then seek to understand and mitigate the portfolio risk through appropriate hedging mechanisms.

Since at-site climate records are usually short, and it is difficult to pull together global coverage, we considered the use of global, gridded daily rainfall estimated by two differ- ent climate re-analysis models, from NCAR with a 164-year record, and from the ERA-20C with a 111-year record. These models embody the same physics of ocean-atmosphere circulation that is used in the models used for seasonal climate forecasts, or for the projection of future climates. However, they are run over a long historical period and are "corrected" daily over that period to best match the observed surface temperature and pressure data for each historical day. Since the number of observations available varies over the histori- 
cal period, and the models have different spatial resolution and correction schemes, their retrospective projections do not always agree. Rather, just as the IPCC models for future projections represent an ensemble of possibilities, so do the retrospective or re-analysis simulations. We expect that the large-scale features and teleconnections in these models will be similar, but the precise magnitudes of events at specific locations on specific days and years will not match. Consequently, our approach considers the yearly number of events that exceed a specified quantile computed internally for that location for each such model. In other work, this quantilebased approach has been recognized as effective at addressing the biases in each individual model's projections relative to observations.

Our investigations of selected, representative mining portfolios demonstrate that there is significant spatial and temporal clustering in the exposure of mines to the two criteria we considered, a 100-year, 1-day annual maximum rainfall event, and a 10-year, 30-day annual maximum rainfall event. In some cases, for the worst year in the 164-year record, the total number of exceedances of a 10 -year event, i.e. with a yearly probability of occurrence of 0.1 of the residual risk at any given site, was very close to the total number of mines under consideration. This happens because there are several independent events in that year at multiple sites that exceed the design threshold. The consequence is that the portfolio exposure in this setting is much, much greater than the nominal $p m$ (i.e. the probability of exceedance at each mine multiplied by the number of mines). There is also evidence that the frequency of exceedance of such events at the scale of the mine portfolio is increasing over time, and that pronounced decadal variations in this exposure risk are notable for all four companies analysed.

In this paper, we considered two financial metrics for weighting the exposure to the residual risk at each site. These were an estimation of the revenue generated by each mine (calculated as production multiplied by the commodity price) for the most recent year, and the NAV estimated for each mine in a recent valuation completed by mining financial research analysts. The exposure of the portfolio rather than a single mine is of interest, in particular to indicate to an investor the potential relative impact of a temporary or permanent production disruption as a result of the risks discussed above on a given company's financial performance. Since the likely loss at each mine if the design event is exceeded is hard to estimate a priori, even by the mining company, one needs an approach that allows for an appropriate weighting of the potential portfolio losses. We intend for the index we developed to be used for sensitivity analysis, to explore how the total portfolio exposure may scale depending on various levels of designed risk protection. Consequently, we assumed that the loss at a certain level of design (average annual probability of exceedance of the annual maximum rainfall) is proportional to either the revenue at each site, or to the NAV at each site, for each event that exceeds the design level. To es- timate the potential impact of temporary production disruptions that a given mine may experience relatively frequently (e.g. with a 10-year return period), we use an approximation of the revenue by mine as a proxy to weight the number of events of that magnitude experience at each site. For more catastrophic events, e.g. those related to the 100-year annual maximum rainfall that may result in permanent mine closure (or a full write-off of a given asset), we weight the frequency of such events in each year by the NAV of each mine, providing a measure of the portfolio exposure. By applying these weights, we discovered the following for the portfolio financial exposure:

- typically increases over time, with decadal variations, as expected given the space and time clustering of the frequency of exceedances;

- the tail of the probability distribution of portfolio risk for different companies may behave very differently.

These observations reflect geographical aspects of the structure of portfolio risk, and could motivate a company to hedge such risks using parametric or index insurance mechanisms or other financial risk management instruments. For an investor a characterization of the geographical nature of risk, as well as that of portfolio risk can permit risk balancing strategies through an appropriate weighting of companies, sectors or geographies.

Furthermore, this same methodology could be employed at the investor portfolio level rather than at the company level. Investors often own a collection of companies, each with a subset of assets that are inherently exposed to their own subsets of risks. Investor portfolios could be disaggregated into their individual components (asset by asset) and different portfolio constructs could be assigned different risks based on their exposure to extreme rain events. Rebalancing exercises could consider effects over both space and time to the risks considered in this paper.

A key question that emerges is whether these climate risk factors actually translate into significant financial risks relative to other financial risk factors associated with investments in mining or other multi-national enterprises. The answer to this question requires a disclosure from mining companies of their design processes, the associated residual risk and estimate of the loss incurred if a failure event occurs. A first part of this process is an internal assessment of these factors by mining companies, and hence a first-order impact of our paper could be a self-examination of these issues by mining companies, and the use of the resulting information to re-evaluate their risk management processes. We know that losses from some such events can be significant. Reported mining-related losses from the extreme rainfall event in the Atacama Desert in Chile in March 2015 were estimated to be of the order of USD 1 billion insured, and a like amount uninsured. This compares with the USD 1.6 billion in capital expenditures associated with the desalination and pumping 
project for mining in the same region, which attracted significant attention as an example of water risk. In the absence of more detailed disclosure and internal assessment by mining companies, the best we can do is provide relative rankings of the financial exposure of different companies having distinct portfolios. Logically we expect extreme rainfall events that result in catastrophic loss will impact a given company's financial performance; however, the analysis we perform in this paper is solely theoretical and on a relative basis. Getting more detailed information is therefore a prerequisite to investigate the matter further, and in particular questions such as the salience of climate risk relative to price volatility risk for mining companies, and the feedbacks between these aspects (for instance a climate event leading to the stoppage of large clustered mines would impact commodity prices). Price volatility has been considered in discounted cash flows analysis and real-option modelling of mining assets (see for instance Garrido-Lagos and Zhang, 2012; Baurens, 2010), and the inclusion of extreme events in such models is being explored by members of our team at Columbia; however, linking actual events to losses in a direct way needs to be done to fill the gap.

Social conflict is often cited as the most significant waterrelated risk for mining companies. In our analysis here, we considered a term in Eq. (1) for impacts external to the mine, which the mine owner would be liable for (and hence would directly impact that company's financial performance). However, in the examples in this paper we did not develop estimates for the potential liabilities that would come from the ecological, environmental and social impacts downstream of the failure of mine infrastructure. This is an area where we plan to make further headway, in collaboration with WWF Norway, who has developed a database that maps mines, ecosystems and human habitations that are interconnected by the natural drainage network, and hence are the potential for direct impact if mine systems are overcome by extreme rainfall.

A second area of social conflict related to water emerges not from pollution or flooding, but from water scarcity. For an existing mine, this is manifest during a severe, sustained drought. In this setting, even existing senior water rights or water access arrangements can be strained. The basic idea of residual risk for climate extremes that we introduced in this paper can also be extended to the drought case, with the proviso that a quantification of the competition for water under these conditions that would be faced by the mining company, and an assessment of their plans to deal with such contingencies would be required. While some generalized products (e.g. WRI, 2015) claim to provide estimates for such water risks, we believe that mining companies need to assess these risks internally relative to different severity and durations possible for droughts; integrate the analyses into their risk management processes and provide disclosure of these risks at a site by site level. This site level analysis could then be aggregated to determine the financial impact from the investor and regulator perspectives.

We noted earlier that climate information is marked by uncertainty and structured space-time variability. We were able to tap a few realizations of such variability using two climate re-analysis products. However, many more such products are available from 1948 to present, 1979 to present and 1997 to present. For drought there are also global reconstructions of palaeo-drought from tree rings and other proxies, which provide a window into climate variability over the last 5 centuries or more. The spatial resolution of climate information, as well as the fidelity to ground observations varies. Similarly, ground-based observations of varying duration are available. It is indeed possible to build nonstationary, stochastic simulation models that integrate across such sources of information and provide simulations that can be used to reduce the uncertainty associated with the risk of climate extremes that may vary across space and time. Our past work has addressed some of these issues, and we expect that the tools developed for those cases can also be applied here. However, a bigger issue that needs to be addressed is the estimation of potential financial loss and the attendant uncertainty covering both impacts internal and external to the mine.

To facilitate climate informed portfolio risk analyses, we have developed a web-based app, using the R statistical platform, which can accept the location of multiple sites - mines or other assets in a portfolio; the specification of the duration and rarity of the rainfall extremes of interest; estimates of the financial exposure at each site; and other parameters from a user, and allow them to compute the portfolio risk measures presented here. A selection of the climate data that are available to use is also available.

Data availability. Climate data can be found at the following links: 20CR daily precipitation data: http://www.esrl.noaa.gov/psd/ cgi-bin/db_search/DBSearch.pl?Dataset=NOAA-CIRES+20th+ Century+Reanalysis+Version+2c\&Variable $=$ Precipitation+Rate, ERA-20C: http://rda.ucar.edu/datasets/ds626.0/index.html\#cgi-bin/ datasets/getSubset?dsnum=626.0\&action=customizeGrML\&_da= $y \& s o=\operatorname{RgpNO} \&$ gindex $=15$. Broker reports are available on the Thomson Reuters platform. 


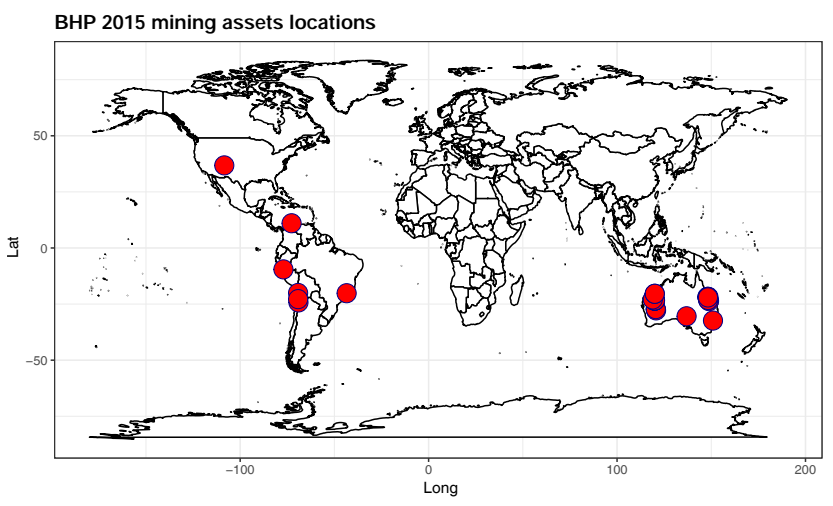

Figure A1. Map of BHP Billiton 2015 mining assets.

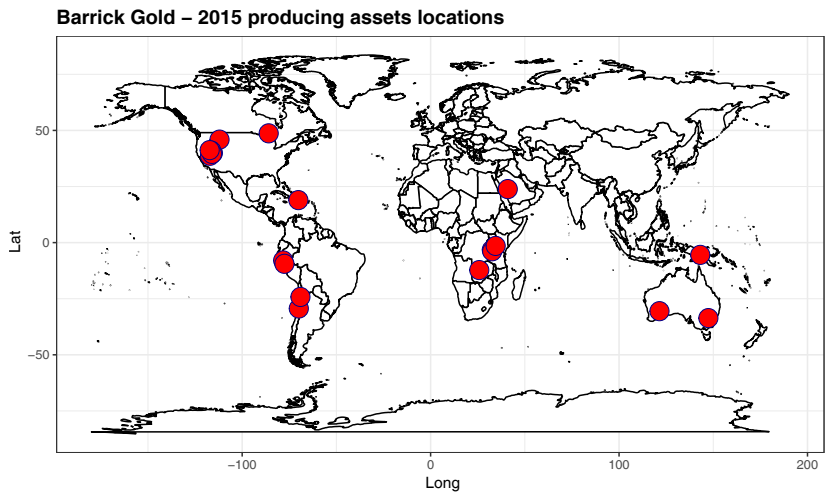

Figure A2. Map of Barrick Gold 2015 producing assets.

\section{Appendix A: Portfolio description}

In this appendix, a description of each of the mine portfolios studied is presented. For each portfolio, asset locations are provided. Estimated revenues introduced in Sect. 4.2.1 are also shown here for Barrick Gold and Newmont Corporation. However, NAV values introduced in Sect. 4.2.2 are not provided, as they came from a non-public data source.

\section{A1 BHP Billiton (2015) mining assets (BHP Billiton, 2016)}

Information on the BHP Billiton mining portfolio was obtained by cross-referencing the mining assets mentioned in (BHP Billiton, 2016) and the coordinates from an internet search. It comprised 38 mine sites. It is important to note groups of mines such as the Hammersley system in Pilbara were disaggregated. The orebody mines in particular were each considered as a given asset. However, due to the difficulty of finding information, they were all assigned the coordinates approximate coordinates corresponding to the Hammersley joint venture.

As can be seen from the map below, there is a high clustering in two regions of Australia: Pilbara and North East

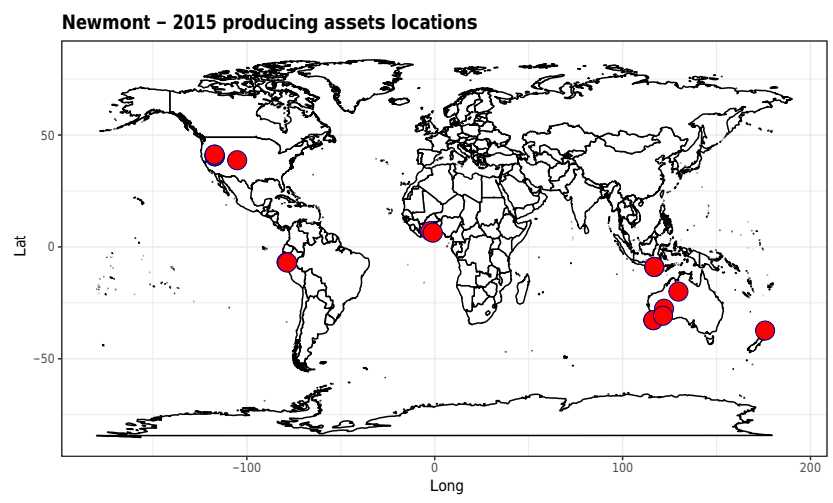

Figure A3. Map of Newmont 2015 producing assets.

Queensland, which are important iron and coal producing areas respectively.

\section{A2 Barrick Gold 2015 producing assets (Barrick Gold Corporation, 2016)}

Information on the Barrick Gold mining portfolio was obtained by cross-referencing the production information mentioned in Barrick Gold Corporation (2016) and the coordinates from an internet search. It comprised 19 gold and copper mines. Commodity price information was retrieved from Word Bank (2016).

\section{A3 Newmont 2015 producing assets (Newmont Mining Corporation, 2016)}

Information on the Newmont Corporation mining portfolio was obtained by cross-referencing the production information mentioned in Newmont Mining Corporation (2016) and the coordinates from an internet search. It comprised 16 gold and copper mines. Commodity price information was retrieved from Word Bank (2016).

\section{A4 Rio Tinto 2015 mining assets (Rio Tinto, 2016)}

Information on the Rio Tinto mining portfolio was obtained by cross-referencing the mining assets mentioned in Rio Tinto (2016) and the coordinates found through an internet search. It comprised 40 mine sites.

\section{A5 Barrick Gold mining assets valued in TD Securities (2016a)}

On the following map, asset symbols are proportional to the share of the total NAV they represent Fig. A5.

\section{A6 Newmont Corporation mining assets valued in TD Securities (2016b)}

On the following map, asset symbols are proportional to the share of the total NAV they represent Fig. A6. 


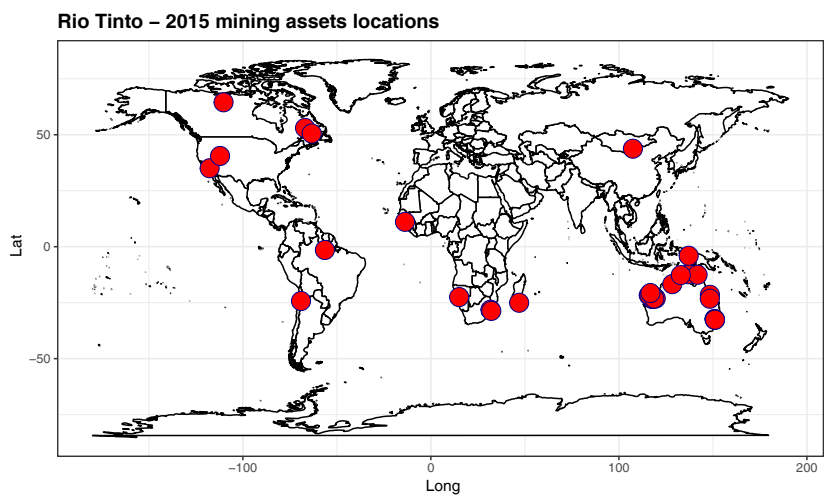

Figure A4. Map of Rio Tinto 2015 mining assets.

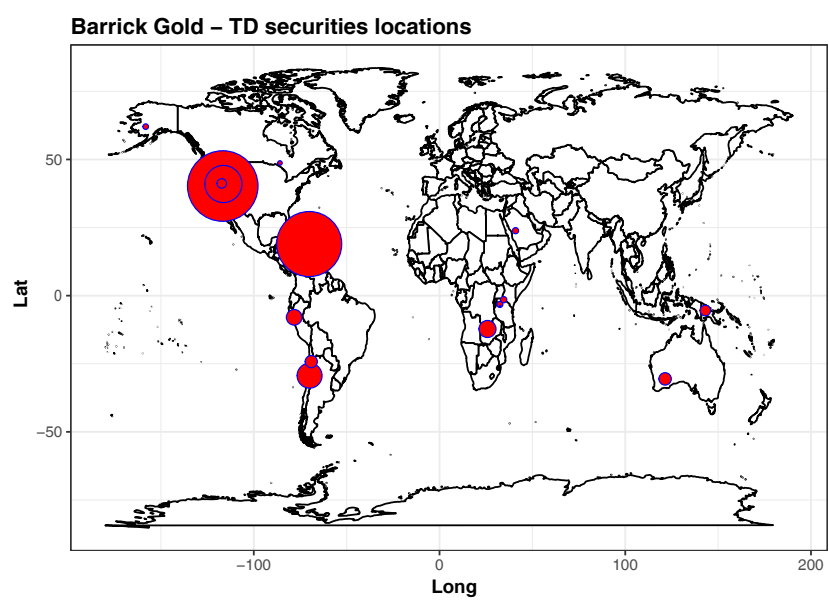

Figure A5. Map of Barrick Gold assets reported in TD Securities (2016a).

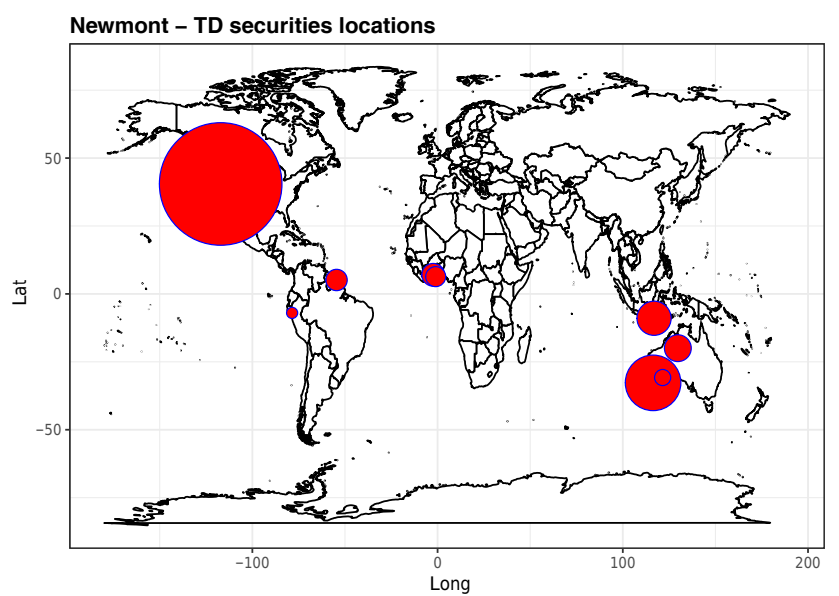

Figure A6. Map of Newmont Corporation assets reported in TD Securities (2016b).

The similarity between Barrick Gold and Newmont Corporation in terms of the localization of their assets and the value corresponding to given locations is here confirmed. 
Table A1. 2015 mining asset coordinates for BHP Billiton.

\begin{tabular}{|c|c|c|c|c|c|}
\hline Asset name & Latitude & Longitude & $\begin{array}{l}\text { Primary } \\
\text { commodity }\end{array}$ & Year & Ownership \\
\hline Goonyella Riverside & -21.80889 & 147.97861 & Coal & 2015 & $50 \%$ \\
\hline Broadmeadow & -21.8049 & 147.9845 & Coal & 2015 & $50 \%$ \\
\hline Daunia & -22.05892 & 148.29836 & Coal & 2015 & $50 \%$ \\
\hline Caval Ridge & -22.14199 & 148.06098 & Coal & 2015 & $50 \%$ \\
\hline Peak Downs & -22.254 & 148.196 & Coal & 2015 & $50 \%$ \\
\hline Saraji & -22.36944 & 148.29111 & Coal & 2015 & $50 \%$ \\
\hline Blackwater & -23.68556 & 148.8075 & Coal & 2015 & $50 \%$ \\
\hline Norwich Park & -22.61583 & 148.42944 & Coal & 2015 & $50 \%$ \\
\hline Gregory & -23.17222 & 148.35639 & Coal & 2015 & $50 \%$ \\
\hline Crinum & -23.17222 & 148.35639 & Coal & 2015 & $50 \%$ \\
\hline South Walker Creek & -21.78457 & 148.47162 & Coal & 2015 & $80 \%$ \\
\hline Poitrel & -22.04111 & 148.23444 & Coal & 2015 & $80 \%$ \\
\hline Mt Arthur & -32.34833 & 150.90556 & Coal & 2015 & $100 \%$ \\
\hline San Juan & 36.80151 & -108.43064 & Coal & 2015 & $100 \%$ \\
\hline Cerrejon & 11.018 & -72.714 & Coal & 2015 & $33 \%$ \\
\hline Antamina & -9.53917 & -77.05 & Copper & 2015 & $34 \%$ \\
\hline Escondida & -24.26889 & -69.07466 & Copper & 2015 & $58 \%$ \\
\hline Olympic Dam & -30.44 & 136.88889 & Copper & 2015 & $100 \%$ \\
\hline Pampa Norte Cerro Colorado & -24.26667 & -69.06667 & Copper & 2015 & $100 \%$ \\
\hline Pampa Norte Spence & -24.26667 & -69.06667 & Copper & 2015 & $100 \%$ \\
\hline Cliffs & -27.31306 & 120.55306 & Nickel & 2015 & $100 \%$ \\
\hline Leinster & -27.81424 & 120.70243 & Nickel & 2015 & $100 \%$ \\
\hline Mt Keith & -27.23056 & 120.545 & Nickel & 2015 & $100 \%$ \\
\hline Mt Whaleback & -23.36536 & 119.6754 & Iron Ore & 2015 & $85 \%$ \\
\hline Orebody 18 & -23.386157 & 119.988638 & Iron Ore & 2015 & $85 \%$ \\
\hline Orebody 23 & -23.386157 & 119.988638 & Iron Ore & 2015 & $85 \%$ \\
\hline Orebody 24 & -23.386157 & 119.988638 & Iron Ore & 2015 & $85 \%$ \\
\hline Orebody 25 & -23.386157 & 119.988638 & Iron Ore & 2015 & $85 \%$ \\
\hline Orebody 29 & -23.386157 & 119.988638 & Iron Ore & 2015 & $85 \%$ \\
\hline Orebody 30 & -23.386157 & 119.988638 & Iron Ore & 2015 & $85 \%$ \\
\hline Orebody 35 & -23.386157 & 119.988638 & Iron Ore & 2015 & $85 \%$ \\
\hline Yandi & -22.71889 & 119.06611 & Iron Ore & 2015 & $85 \%$ \\
\hline Jimblebar & -23.38083 & 120.13806 & Iron Ore & 2015 & $85 \%$ \\
\hline Wheelarra & -23.38145 & 120.13146 & Iron Ore & 2015 & $51 \%$ \\
\hline Area C & -22.92362 & 118.97679 & Iron Ore & 2015 & $85 \%$ \\
\hline Yarrie & -20.417278 & 120.0100995 & Iron Ore & 2015 & $85 \%$ \\
\hline Nimingarra & -20.417278 & 120.0100995 & Iron Ore & 2015 & $85 \%$ \\
\hline Samarco & -20.16149 & -43.50515 & Iron Ore & 2015 & $50 \%$ \\
\hline
\end{tabular}


Table A2. Mining asset coordinates and attributable revenue per mine for Barrick gold for 2015.

\begin{tabular}{lllrrrrr}
\hline Asset name & Primary & Commodity & Latitude & Longitude & Ownership & $\begin{array}{c}\text { Attributable } \\
\text { production }\end{array}$ & Unit \\
& commodity & & & & & & \\
Bald Mountain & Gold & Gold & 39.94139 & -115.543 & $100 \%$ & $1.91 \times 10^{5}$ & ounces \\
Bulyanhulu & Gold & Gold & -3.22344 & 32.48616 & $64 \%$ & $2.74 \times 10^{5}$ & ounces \\
Buzwagi & Gold & Gold & -3.861 & 32.67 & $64 \%$ & $1.71 \times 10^{5}$ & ounces \\
Cortez & Gold & Gold & 40.16973 & -116.608 & $100 \%$ & $9.99 \times 10^{5}$ & ounces \\
Cowal & Gold & Gold & -33.6374 & 147.4053 & $100 \%$ & $1.56 \times 10^{5}$ & ounces \\
Golden Sunlight & Gold & Gold & 45.90578 & -112.022 & $100 \%$ & $6.80 \times 10^{4}$ & ounces \\
Goldstrike & Gold & Gold & 40.98072 & -116.381 & $100 \%$ & $1.05 \times 10^{6}$ & ounces \\
Hemlo & Gold & Gold & 48.69755 & -85.9252 & $100 \%$ & $2.19 \times 10^{5}$ & ounces \\
Jabal Sayid & Copper & Copper & 23.85226 & 40.94042 & $100 \%$ & $6.00 \times 10^{6}$ & pounds \\
Kalgoorlie & Gold & Gold & -30.553 & 121.45 & $50 \%$ & $3.20 \times 10^{5}$ & ounces \\
Lagunas Norte & Gold & Gold & -7.94806 & -78.2447 & $100 \%$ & $5.60 \times 10^{5}$ & ounces \\
Lumwana & Copper & Copper & -12.2362 & 25.82228 & $100 \%$ & $2.87 \times 10^{8}$ & pounds \\
North Mara & Gold & Gold & -1.47333 & 34.51639 & $64 \%$ & $2.87 \times 10^{5}$ & ounces \\
Pierina & Gold & Gold & -9.44694 & -77.5869 & $100 \%$ & $5.40 \times 10^{4}$ & ounces \\
Porgera & Gold & Gold & -5.465 & 143.095 & $48 \%$ & $4.36 \times 10^{5}$ & ounces \\
Pueblo Viejo & Gold & Gold & 18.93861 & -70.1739 & $60 \%$ & $5.72 \times 10^{5}$ & ounces \\
Round Mountain & Gold & Gold & 38.70389 & -117.077 & $50 \%$ & $1.92 \times 10^{5}$ & ounces \\
Ruby Hill & Gold & Gold & 39.52722 & -115.987 & $100 \%$ & $1.00 \times 10^{4}$ & ounces \\
Turquoise Ridge & Gold & Gold & 41.21639 & -117.256 & $75 \%$ & $2.17 \times 10^{5}$ & ounces \\
Veladero & Gold & Gold & -29.3714 & -69.9528 & $100 \%$ & $6.02 \times 10^{5}$ & ounces \\
Zaldivar & Copper & Copper & -24.2186 & -69.0678 & $100 \%$ & $2.18 \times 10^{8}$ & pounds \\
\hline & & & & & & &
\end{tabular}

Table A3. Mining asset coordinates and attributable production per mine for Newmont Corporation for 2015.

\begin{tabular}{lllrrrrr}
\hline Asset name & $\begin{array}{l}\text { Primary } \\
\text { commodity }\end{array}$ & Commodity & Latitude & Longitude & Ownership & $\begin{array}{c}\text { Attributable } \\
\text { production }\end{array}$ & Unit \\
& Ghafo & & & & & & \\
Akyem & Gold & Gold & 7.03076 & -2.35953 & $100 \%$ & $3.32 \times 10^{5}$ & ounces \\
Batu Hijau & Gold & Gold & 6.35876 & -1.02607 & $100 \%$ & $4.73 \times 10^{5}$ & ounces \\
Batu Hijau & Gold & Copper & -8.96667 & 116.8667 & $48.50 \%$ & $3.28 \times 10^{5}$ & ounces \\
Boddington & Gold & Gold & -32.7417 & 116.3469 & $100 \%$ & $7.94 \times 10^{5}$ & ounces \\
Boddington & Gold & Copper & -32.7417 & 116.3469 & $100 \%$ & $7.90 \times 10^{7}$ & pounds \\
Carlin & Gold & Gold & 40.4651 & -117.102 & $100 \%$ & $8.86 \times 10^{5}$ & ounces \\
CC and V & Gold & Gold & 38.72387 & -105.153 & $100 \%$ & $8.10 \times 10^{4}$ & ounces \\
Duketon & Gold & Gold & -27.642 & 122.044 & $19.45 \%$ & $5.70 \times 10^{4}$ & ounces \\
Kalgoorlie & Gold & Gold & -30.7781 & 121.505 & $50 \%$ & $3.16 \times 10^{5}$ & ounces \\
La Zanja & Gold & Gold & -6.82902 & -78.8941 & $47 \%$ & $6.60 \times 10^{4}$ & ounces \\
Phoenix & Gold & Gold & 40.53917 & -117.122 & $100 \%$ & $2.05 \times 10^{5}$ & ounces \\
Phoenix & Gold & Copper & 40.53917 & -117.122 & $100 \%$ & $4.6 \times 10^{7}$ & pounds \\
Tanami & Gold & Gold & -19.9769 & 129.7139 & $100 \%$ & $\times 10^{5}$ & ounces \\
Turquoise Ridge & Gold & Gold & 41.21639 & -117.256 & $25 \%$ & $6.80 \times 10^{4}$ & ounces \\
Twin Creeks & Gold & Gold & 41.25833 & -117.169 & $100 \%$ & $4.03 \times 10^{5}$ & ounces \\
Waihi & Gold & Gold & -37.393 & 175.838 & $100 \%$ & $1.19 \times 10^{5}$ & ounces \\
Yanacocha & Gold & Gold & -6.99417 & -78.5319 & $51.35 \%$ & $4.71 \mathrm{E} \times 10^{5}$ & ounces \\
\hline
\end{tabular}


Table A4. 2015 mining asset coordinates for Rio Tinto.

\begin{tabular}{|c|c|c|c|c|c|}
\hline Asset name & Latitude & Longitude & $\begin{array}{l}\text { Primary } \\
\text { commodity }\end{array}$ & Year & Ownership \\
\hline Gove & -12.295 & 136.83 & Bauxite & 2015 & $100 \%$ \\
\hline Porto Trombetas & -1.4717486 & -56.3784885 & Bauxite & 2015 & $12 \%$ \\
\hline Sangaredi & 11.1 & -13.77 & Bauxite & 2015 & $23 \%$ \\
\hline Weipa & -12.533 & 141.833 & Bauxite & 2015 & $100 \%$ \\
\hline Boron & 35.0331722 & -117.668687 & Borates & 2015 & $100 \%$ \\
\hline Bengalla & -32.26667 & 150.85 & Coal & 2015 & $32 \%$ \\
\hline Hail Creek & -21.5 & 148.4 & Coal & 2015 & $82 \%$ \\
\hline Hunter Valley & -32.525 & 150.98333 & Coal & 2015 & $80 \%$ \\
\hline Kestrel & -23.23333 & 148.36667 & Coal & 2015 & $80 \%$ \\
\hline Mt Thorley & -32.64726 & 151.07113 & Coal & 2015 & $64 \%$ \\
\hline Warkworth & -32.60694 & 151.09028 & Coal & 2015 & $45 \%$ \\
\hline Zululand Anthracite Colliery & -28.1598 & 31.6875 & Coal & 2015 & $74 \%$ \\
\hline Bingham Canyon & 40.52056 & -112.145 & Copper & 2015 & $100 \%$ \\
\hline Escondida & -24.26889 & -69.07466 & Copper & 2015 & $30 \%$ \\
\hline Grasberg & -4.05667 & 137.11361 & Copper & 2015 & $40 \%$ \\
\hline Oyu Tolgoi & 43.767127 & 107.4462891 & Copper & 2015 & $34 \%$ \\
\hline Argyle & -16.73056 & 128.38389 & Diamonds & 2015 & $100 \%$ \\
\hline Diavik & 64.49643 & -110.27715 & Diamonds & 2015 & $60 \%$ \\
\hline Brockman 2 & -22.59717 & 117.21776 & Iron Ore & 2015 & $100 \%$ \\
\hline Brockman 4 & -22.59717 & 117.21776 & Iron Ore & 2015 & $100 \%$ \\
\hline Marandoo & -22.63806 & 118.13889 & Iron Ore & 2015 & $100 \%$ \\
\hline Mt Tom Price & -22.76821 & 117.76625 & Iron Ore & 2015 & $100 \%$ \\
\hline Nammuldi & -22.41222 & 117.3375 & Iron Ore & 2015 & $100 \%$ \\
\hline Paraburdoo & -23.22917 & 117.57889 & Iron Ore & 2015 & $100 \%$ \\
\hline Western Turner Syncline & -22.66272 & 117.59022 & Iron Ore & 2015 & $100 \%$ \\
\hline Yandicoogina & -22.76389 & 119.225 & Iron Ore & 2015 & $100 \%$ \\
\hline Channar & -23.30167 & 117.78889 & Iron Ore & 2015 & $60 \%$ \\
\hline Eastern Range & -23.24389 & 117.65694 & Iron Ore & 2015 & $54 \%$ \\
\hline Hope Downs 1 & -22.94667 & 119.12306 & Iron Ore & 2015 & $50 \%$ \\
\hline Hope Downs 4 & -23.14583 & 119.57889 & Iron Ore & 2015 & $50 \%$ \\
\hline IOC & 53.04112 & -66.94422 & Iron Ore & 2015 & $59 \%$ \\
\hline Mesa A & -21.68052 & 115.88057 & Iron Ore & 2015 & $53 \%$ \\
\hline Mesa J & -21.75 & 116.24 & Iron Ore & 2015 & $53 \%$ \\
\hline West Angelas & -23.19056 & 118.78806 & Iron Ore & 2015 & $53 \%$ \\
\hline Dampier & -20.7064 & 116.7425 & Salt & 2015 & $68 \%$ \\
\hline QMM & -25.0370535 & 46.9295919 & Titanium & 2015 & $80 \%$ \\
\hline $\mathrm{RBM}$ & -28.6829452 & 32.1305466 & Titanium & 2015 & $74 \%$ \\
\hline RTFT & 50.5457265 & -63.3852768 & Titanium & 2015 & $100 \%$ \\
\hline Ranger & -12.6851397 & 132.9092073 & Uranium & 2015 & $68 \%$ \\
\hline Rössing SJ & -22.509068 & 15.0356483 & Uranium & 2015 & $69 \%$ \\
\hline
\end{tabular}


Table A5. Mining assets valued in TD Securities (2016a) for Barrick Gold.

\begin{tabular}{lrrr}
\hline Asset name & Latitude & Longitude & Ownership \\
\hline Bulyanhulu & -3.22344 & 32.48616 & $64 \%$ \\
Buzwagi & -3.861 & 32.67 & $64 \%$ \\
Cerro Casale & 40.16973 & -116.608 & $75 \%$ \\
Cortez & -27.7906 & -69.2994 & $100 \%$ \\
Donlin Creek & 62.045 & -158.198 & $50 \%$ \\
Goldstrike & 40.98072 & -116.381 & $100 \%$ \\
Hemlo & 48.69755 & -85.9252 & $100 \%$ \\
Jabal Sayid & 23.85226 & 40.94042 & $50 \%$ \\
Kalgoorlie & -30.553 & 121.45 & $50 \%$ \\
Lagunas Norte & -7.94806 & -78.2447 & $100 \%$ \\
Lumwana & -12.2362 & 25.82228 & $100 \%$ \\
North Mara & -1.47333 & 34.51639 & $64 \%$ \\
Pascua-Lama & -29.3231 & -70.0233 & $100 \%$ \\
Porgera & -5.465 & 143.095 & $48 \%$ \\
Pueblo Viejo & 18.93861 & -70.1739 & $60 \%$ \\
Turquoise Ridge & 41.21639 & -117.256 & $75 \%$ \\
Veladero & -29.3714 & -69.9528 & $100 \%$ \\
Zaldivar & -24.2186 & -69.0678 & $50 \%$ \\
Other & $\mathrm{n} / \mathrm{a}$ & $\mathrm{n} / \mathrm{a}$ & $100 \%$ \\
\hline
\end{tabular}

$\mathrm{n} / \mathrm{a}=$ not applicable

Table A6. Mining assets valued in TD Securities (2016b) for Newmont Corporation.

\begin{tabular}{lrrr}
\hline Asset name & Latitude & Longitude & Ownership \\
\hline Nevada & 40.4651 & -117.102 & $100.00 \%$ \\
Cripple Creek \& Victor & 38.72387 & -105.153 & $100.00 \%$ \\
Yanacocha & -6.99417 & -78.5319 & $51.40 \%$ \\
Batu Haijau & -8.96667 & 116.8667 & $44.60 \%$ \\
Boddington & -32.7417 & 116.3469 & $100.00 \%$ \\
Kalgoorlie & -30.7781 & 121.505 & $50.00 \%$ \\
Tanami & -19.9769 & 129.7139 & $100.00 \%$ \\
Ahafo & 7.03076 & -2.35953 & $100.00 \%$ \\
Akyem & 6.35876 & -1.02607 & $100.00 \%$ \\
Conga M \& I & -6.08424 & -78.3616 & $51.40 \%$ \\
Merian & 5.125 & -54.5467 & $75.00 \%$ \\
Other & $\mathrm{n} / \mathrm{a}$ & $\mathrm{n} / \mathrm{a}$ & $100 \%$ \\
\hline
\end{tabular}

$\mathrm{n} / \mathrm{a}=$ not applicable. 


\section{Appendix B: Clustering in time and trend}

In this Appendix, we show the analysis of $N_{t}(p)$ of all the portfolios mentioned in Sect. 5.1.1. We consider both a 1day extreme rainfall event with a 100-year return level and a 30-day extreme rainfall event with a 10-year return level. We also use both the ECMWF and NOAA re-analysis datasets and therefore restrict the time range to 1900-2010 for consistency. The $p$ values from Mann-Kendall tests performed on the time series are indicated above each plot (computations performed for the period 1900-2010).
The main conclusion to be drawn here is that while there seem to exist a positive trend in the 30-day event cases, in general, the significance level is lower when using the ERA$20 \mathrm{C}$ dataset; the $p$ values on the figure show that, at the $5 \%$ level, significant positive trends were detected almost systematically using the 20CR dataset, but that it is only true for certain cases using the ERA-20C data. This emphasizes the need to take a critical approach towards those results, and the value of using multiple re-analysis models.

Furthermore, all the sen slopes for the 100-year event are null, which is due to the fact that sen slopes are computed as the median of the slopes between the points of a given dataset. 

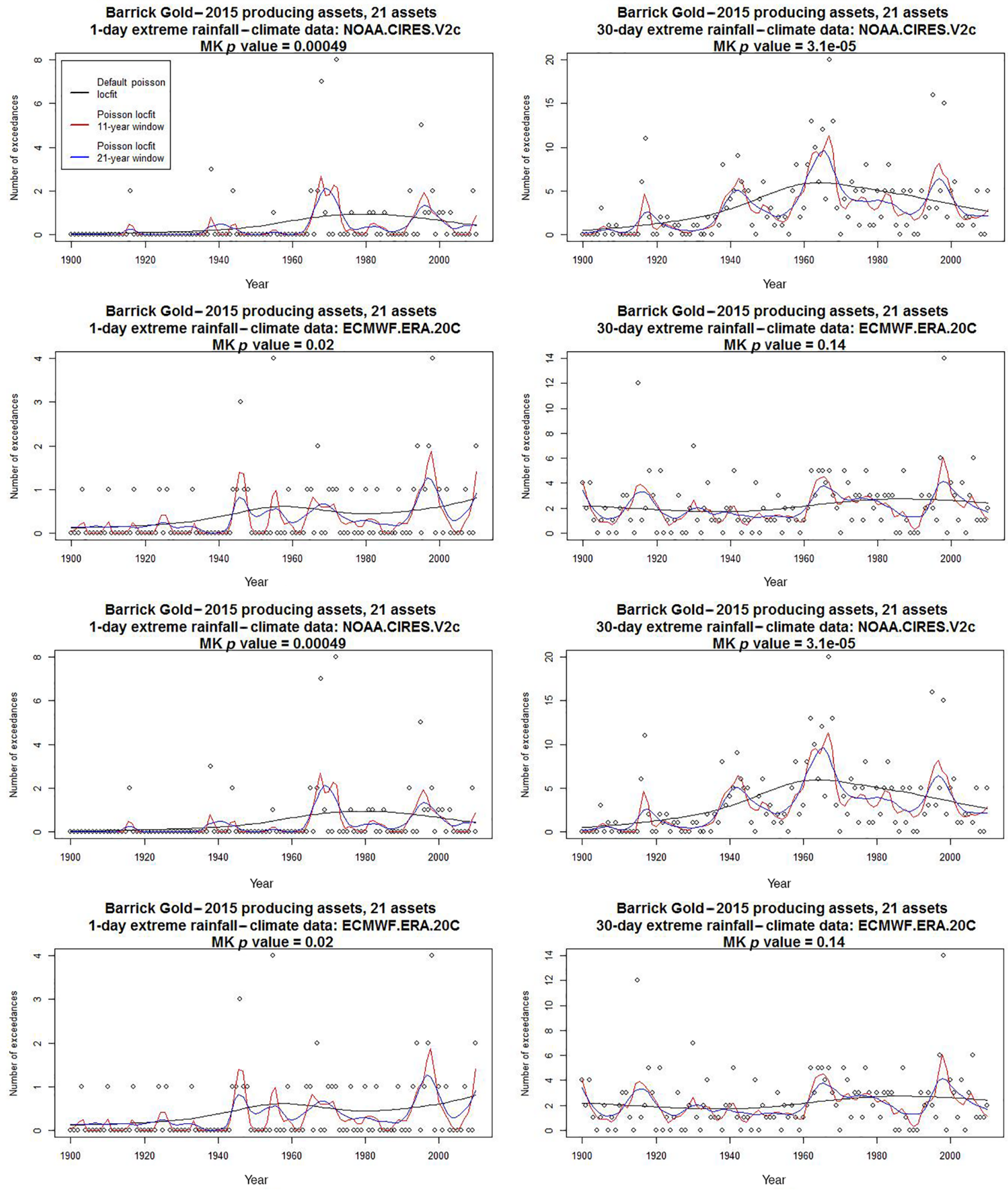

Figure B1. 

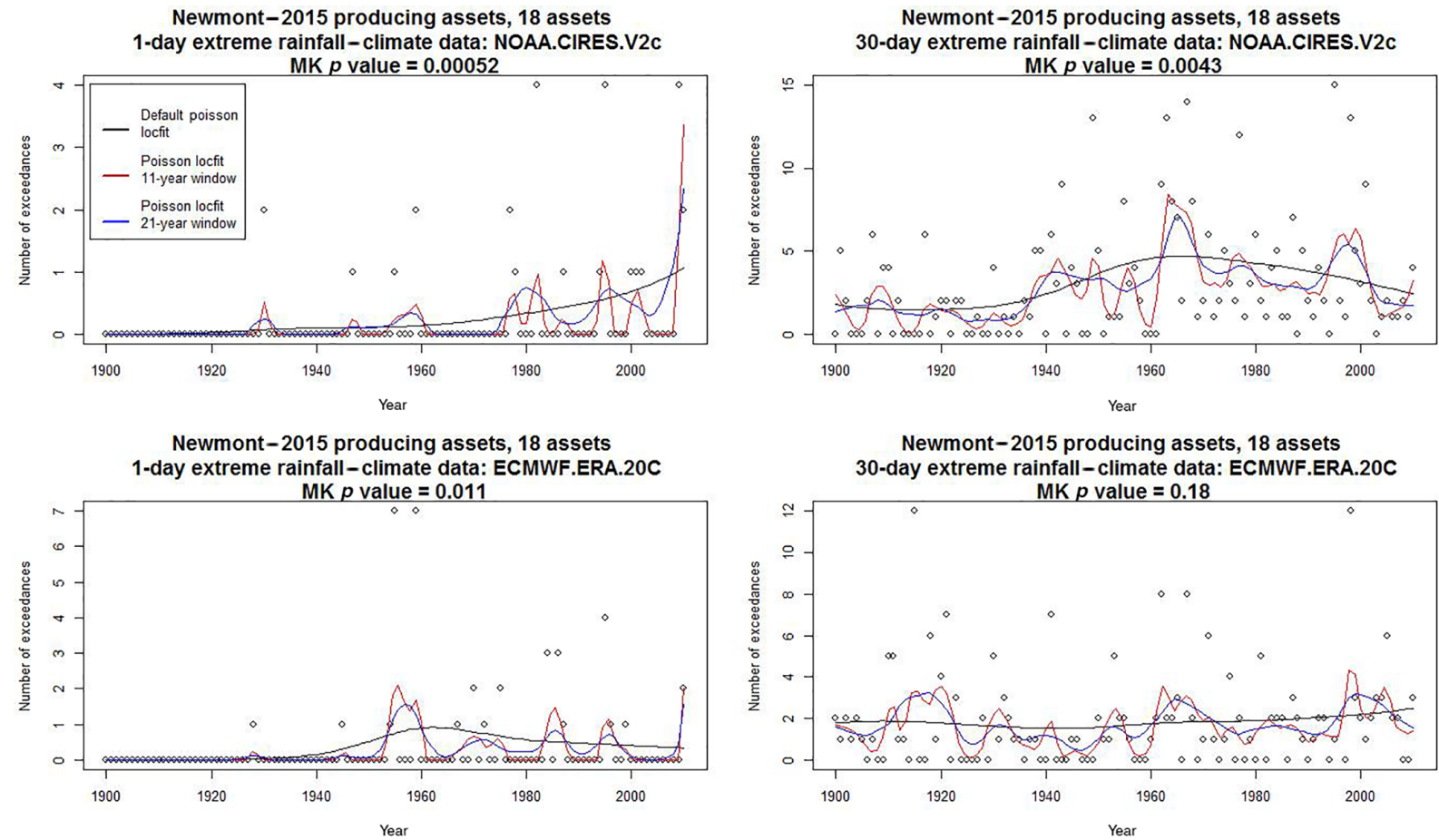

Rio Tinto- 2015 assets, 40 assets
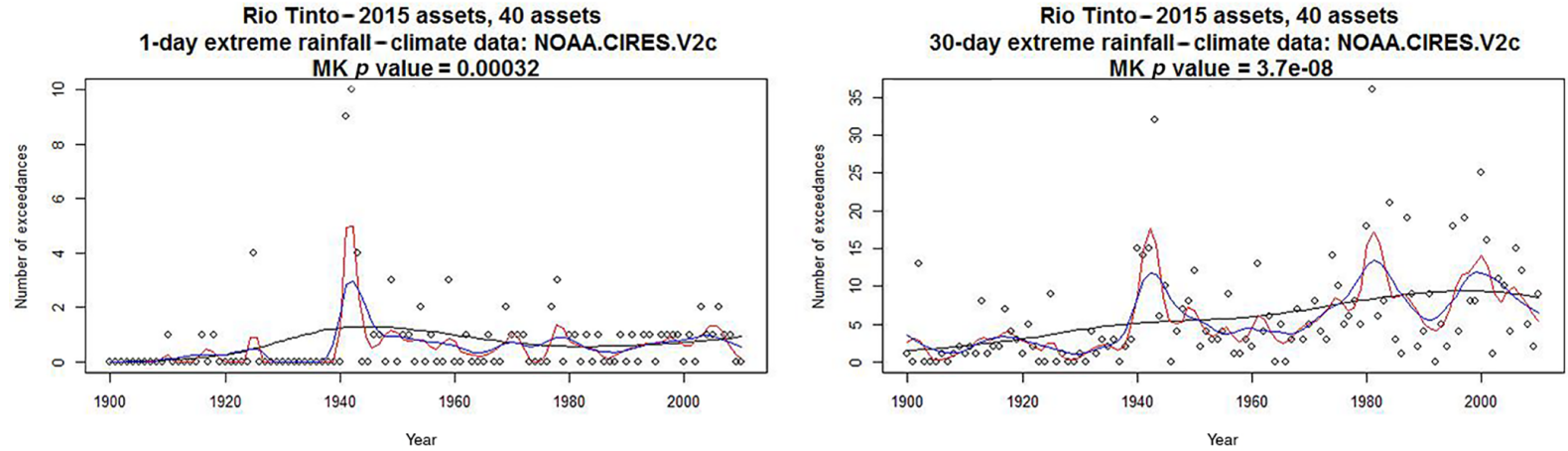

Rio Tinto- 2015 assets, 40 assets
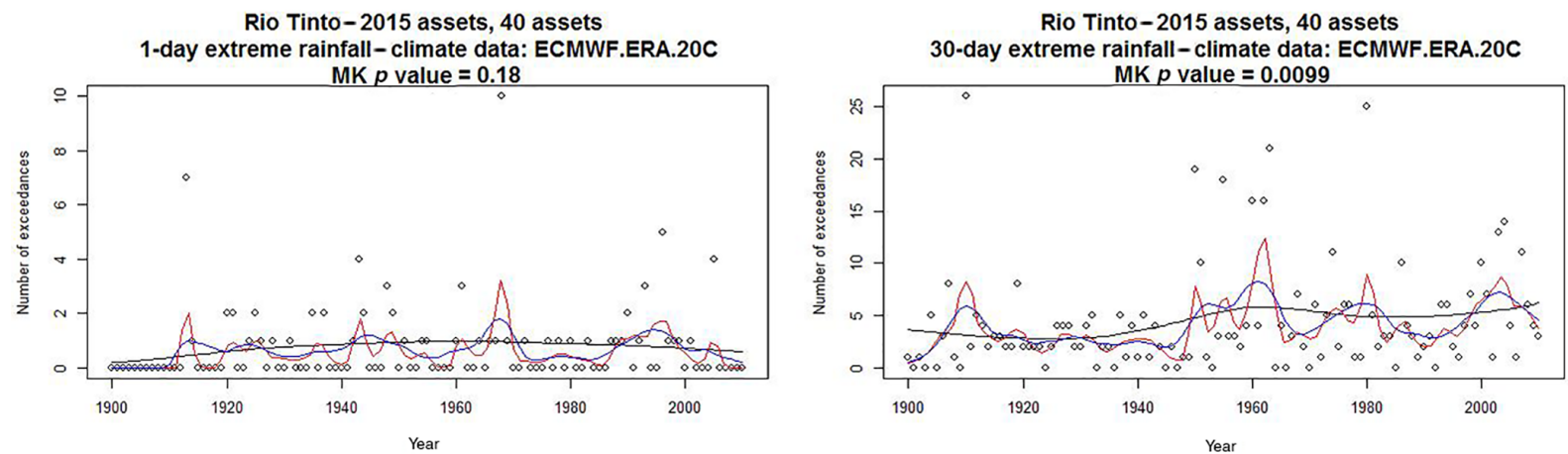

Figure B1. Time series $N_{t}(p)$ of the yearly number of 1-day (left panels) and 30-day (right panels) extreme rainfall events hitting the four mine portfolios computed from two climate datasets: 20CR and ERA-20C. 
Table B1. Mann-Kendall test results for the count of the number of extreme 30-day extreme rainfall event with a 10-year return level on four mine portfolios, using both the NOAA and ECMWF climate datasets (computations performed for the period 1851-2014 for the 20CR data and 1900-2010 for ERA-20C).

\begin{tabular}{lclllll}
\hline & \multicolumn{3}{c}{$20 \mathrm{CR}$} & & \multicolumn{2}{c}{ ERA-20C } \\
\cline { 2 - 3 } \cline { 5 - 6 } Company & $\begin{array}{c}\text { Slope } \\
\text { sign }\end{array}$ & $\begin{array}{l}\text { Sen slope } \\
(p \text { value })\end{array}$ & & $\begin{array}{c}\text { Slope } \\
\text { sign }\end{array}$ & $\begin{array}{l}\text { Sen slope } \\
(p \text { value })\end{array}$ \\
\hline Barrick Gold & + & $0.017\left(2.9 \times 10^{-10}\right)$ & & $0(0.14)$ \\
BHP Billiton & + & $0.016\left(2.9 \times 10^{-10}\right)$ & & $0\left(7.4 \times 10^{-2}\right)$ \\
Newmont Corporation & + & $0.011\left(3.0 \times 10^{-9}\right)$ & & $0(0.18)$ \\
Rio Tinto & + & $0.042\left(2.7 \times 10^{-17}\right)$ & & + & $0.019\left(9.9 \times 10^{-3}\right)$ \\
\hline
\end{tabular}

Table B2. Mann-Kendall test results for the count of the number of extreme 1-day extreme rainfall event with a 100-year return level on four mine portfolios, using both the NOAA and ECMWF climate datasets.

\begin{tabular}{|c|c|c|c|c|}
\hline \multirow[b]{2}{*}{ Company } & \multicolumn{2}{|r|}{$20 \mathrm{CR}$} & \multicolumn{2}{|c|}{ ERA-20C } \\
\hline & $\begin{array}{l}\text { Slope } \\
\text { sign }\end{array}$ & $\begin{array}{l}\text { Sen slope } \\
(p \text { value })\end{array}$ & $\begin{array}{l}\text { Slope } \\
\text { sign }\end{array}$ & $\begin{array}{l}\text { Sen slope } \\
\text { ( } p \text { value) }\end{array}$ \\
\hline Barrick Gold & & $0\left(1.2 \times 10^{-5}\right)$ & & $0\left(2.0 \times 10^{-2}\right)$ \\
\hline BHP Billiton & & $0\left(2.4 \times 10^{-3}\right)$ & & $0(0.65)$ \\
\hline Newmont Corporation & & $0\left(4.4 \times 10^{-5}\right)$ & & $0\left(1.1 \times 10^{-2}\right)$ \\
\hline Rio Tinto & & $0\left(2.8 \times 10^{-9}\right)$ & & $0(0.18)$ \\
\hline
\end{tabular}




\section{Appendix C: Clustering in space}

In this Appendix, we show the cdf's corresponding to the analysis of Sect. 4.1.2, considering both a 1-day extreme event and a 30-day extreme event.

As previously evoked, in each case, the empirical distribution differs significantly from the theoretical Poisson process associated, with, in particular, a fatter tail. This is confirmed by the study of the $r_{k}$ ratios.
While BHP seems to be the portfolio with the most significant tail exposure in terms of number of hits, one should note that the level of disaggregation of the BHP mine groups we decided on implied to consider each of the Orebody mines (a group of mines close to each other in the Pilbara region) as an individual asset; this may or may not correspond to an investor's perspective. In any case, from an investor perspective, what ultimately counts is the value exposed rather than the number of events across a portfolio. 

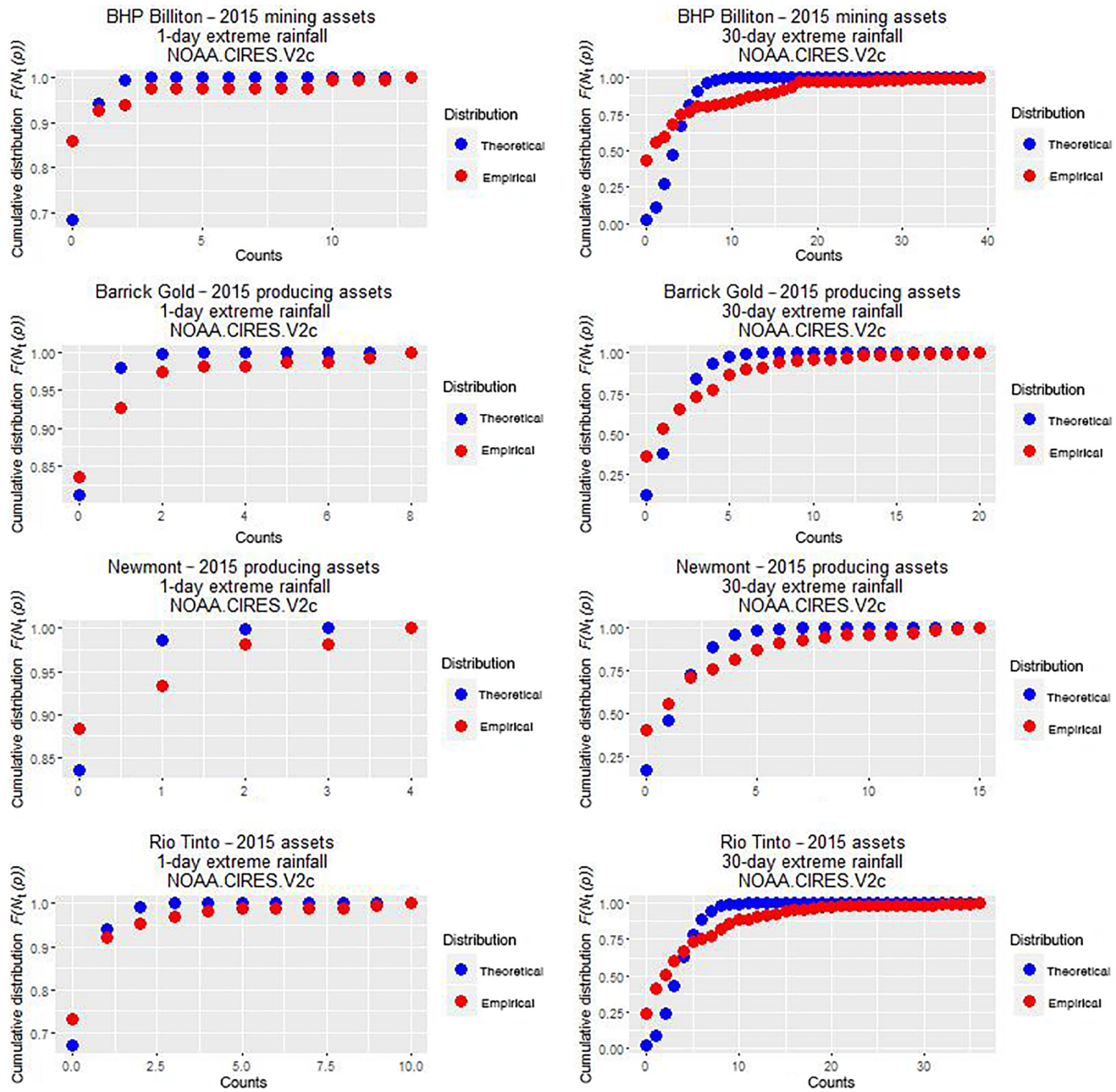

Figure C1. Comparison of the cdf's of the yearly number of 1-day (left panels) and 30-day (right panels) extreme rainfall events hitting the BHP, Barrick Gold, Newmont and Rio Tinto mine portfolios with the corresponding theoretical cdf's assuming independence of events in space and time (Poisson processes). Empirical distributions were derived from the $N_{t}(p)$ time series using the ecdf $R$ function, which computes an empirical cumulative distribution function. The 20CR dataset was used. 

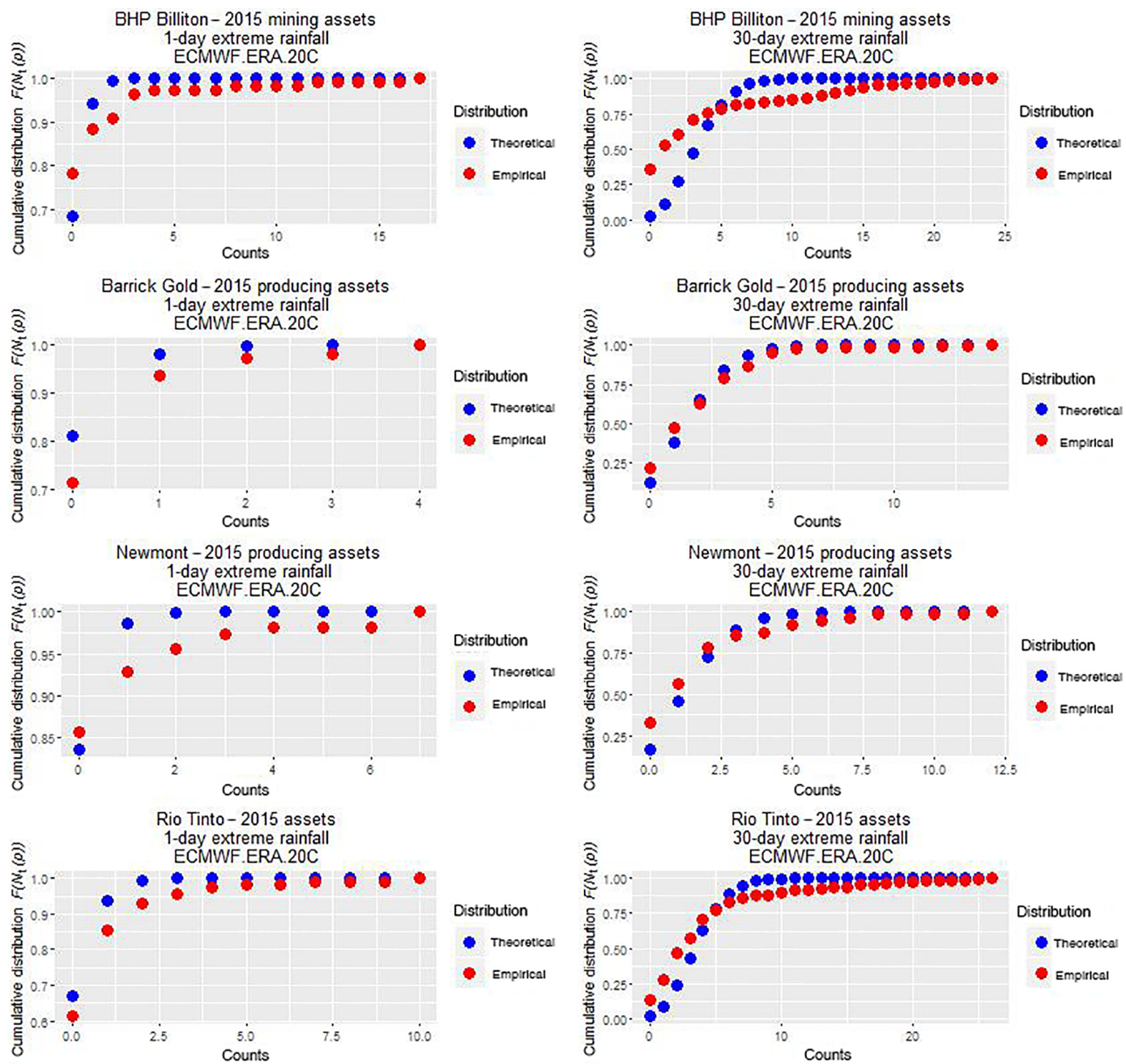

Figure C2. Comparison of the cdf's of the yearly number of 1-day (left panels) and 30-day (right panels) extreme rainfall events hitting the BHP, Barrick Gold, Newmont and Rio Tinto mine portfolios with the corresponding theoretical cdf's assuming independence of events in space and time (Poisson processes). Empirical distributions were derived from the $N_{t}(p)$ time series using the ecdf $R$ function, which computes an empirical cumulative distribution function. The ERA-20C dataset was used. 


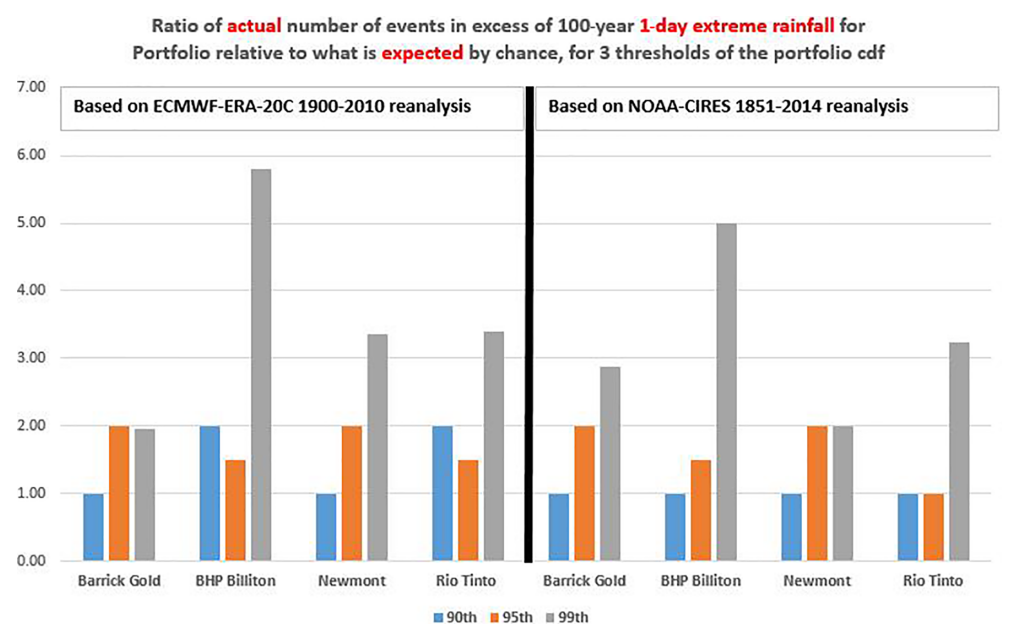

Figure C3. Ratio of the actual number of the number of 10-year, 10-day extreme rainfall events fitting the four portfolio relative to what is expected by chance, for three thresholds of the portfolio cdf.

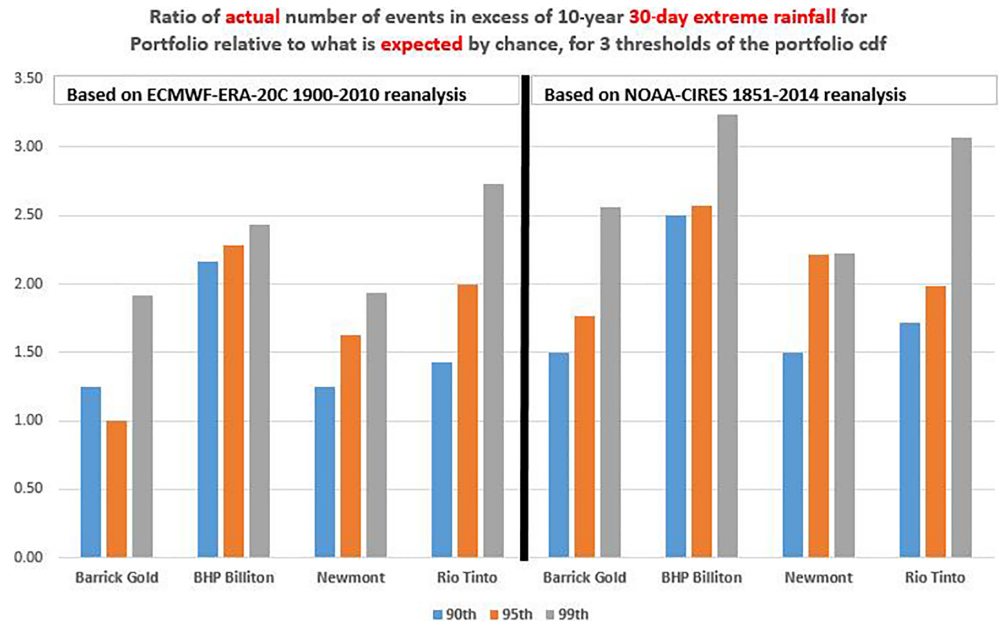

Figure C4. Ratio of the actual number of the number of 10-year, 30-day extreme rainfall events fitting the four portfolio relative to what is expected by chance, for three thresholds of the portfolio cdf. 
Competing interests. The authors declare that they have no conflict of interest.

Acknowledgements. The research presented here was supported by a grant from Norges Bank Investment Management. We acknowledge help from Ajay Vempati for helping compile the NAV values of the mines from broker reports.

Edited by: S. Uhlenbrook

Reviewed by: A. Money and Z. Wang

\section{References}

Adriaens, P., Sun, K., and Gao, R.: Bridging Physical and Financial business Water Risk: waterVar and waterBeta metrics for Equity Portfolio Risk Assessment, University of Michigan, AnnArbor, 2014.

Alemohammad, S. H., Fang, B., Konings, A. G., Green, J. K., Kolassa, J., Prigent, C., Aires, F., Miralles, D., and Gentine, P.: Water, Energy, and Carbon with Artificial Neural Networks (WECANN): A statistically-based estimate of global surface turbulent fluxes using solar-induced fluorescence, Biogeosciences Discuss., doi:10.5194/bg-2016-495, in review, 2016.

Barrick Gold Corporation: Annual Report 2015, Barrick Gold Corporation, Toronto, Canada, 2016.

Baurens, S.: Valuation of Mining Assets, Basinvest, Zurich, Switzerland, 2010.

BHP Billiton: Pampa Norte - Spence, Extreme Rainfall Event, 2427 March 2015, BHP Billiton, Santiago, Chile, 2015.

BHP Billiton: Resourcing Global Growth - Annual report 2015, BHP Billiton, Melbourne, 2016.

Biondi, F. G.: North Pacific Decadal climate variability since 1661, J. Climate, 14, 5-10, 2001.

Blanchet, J. and Dolan, C. I.: Pricing Mines with Uncertain Catastrophe Risk, in preparation, 2016.

Bloomberg: Record Coal Price Risk Gaining on Australian Rain: Commodities, available at Bloomberg: http://www.bloomberg.com/news/articles/2011-10-11/

record-coal-price-risk-gaining-on-australian-rain-commodities, last access: 12 Ocotber 2011.

Bloomberg: Coal's Answer to Decade-Low Prices Is Even Lower Prices, Bloomberg, Chicago, Illinois, USA, 14 September 2015.

Bocci, C., Caporali, E., and Alessandra, P.: Geoadditive modeling for extreme rainfall data, Adv. Stat. Anal., 97, 181-193, 2012.

BP: Statistical Review of World Energy 2015, available at BP: http://www.bp.com/en/global/corporate/energy-economics/ statistical-review-of-world-energy.html, last access: 21 March 2016.

Cayan, D. R., Redmond, K. T., and Riddle, L. G.: ENSO and hydrologic extremes in the western United States, J. Climate, 12, 2881-2893, 1999.

Chambers, M.: Coking coal prices to skyrocket as stockpiles dry up, available at The Australian Business Review: http://www.theaustralian.com.au/business/ coking-coal-prices-to-skyrocket-as-stockpiles-dry-up/ story-e6frg8zx-1225993253543, last access: 24 January 2011.
Coles, S.: An Introduction to the Modeling of Extreme Values, Springer, London, 2001.

Dai, A. and Trenberth, K.: Global Variations in Droughts and Wet Spells: 1900-1995, Geophys. Res. Lett., 25, 3367-3370, 1998.

Dee, D. P., Balmaseda, M., Balsamo, G., Engelen, R., Simmons, A. J., and Thépaut, J. N.: Toward a consistent reanalysis of the climate system, B. Am. Meteorol. Soc., 95, 1235-1248, 2014.

Fekete, B., Vörösmarty, C., and Grabs, W.: High-resolution fields of global runoff combining observed river discharge and simulated water balances, Global Biogeochem. Cy., doi:10.1029/1999GB001254, http://www.bafg.de/GRDC/EN/ 03_dtprdcts/33_CmpR/unh_grdc_node.html, (last access: April 2017), 2002.

Frankcombe, L. M., Von Der Heydt, A., and Dijkstra, H. A.: North Atalantic multidecadal climate variability: an investifgation of dominant time scales and processes, J. Climate, 23, 326-3636, 2010.

Garrido-Lagos, J. P. and Zhang, S. X.: A Real Options Model to Value Multiple Mining Investment Options in a Single Instant of Time, Real Options - Theory Meets Practice, London, 2012.

Gershunov, A. and Barnett, T. P.: ENSO influence on intraseasonal extreme rainfall and temperature frequencies in the contiguous United States: Observations and model results, J. Climate, 11, 1575-1609, 1998.

Gilleland, E. and Katz, R. W.: extRemes 2.0: An Extreme Value Analysis Package in R, J. Stat. Softw., 72, 1-39, doi:10.18637/jss.v072.i08, 2016.

Grimm, A. M. and Tedeschi, R. G.: ENSO and extreme rainfall events in South America, J. Climate, 22, 1589-1609, 2009.

Hailegeorgis, T. T. and Alfredsen, K.: Analyses of extreme precipitation and runoff events including uncertainties and reliability in design and management of urban water infrastructure, J. Hydrol., 544, 290-305, 2017.

Heber, A.: Storm impacts Queensland coal supply, Australian Mining, Melbourne, Australia, 29 January 2013.

Helsel, D. and Hirsch, R.: Chapter 12: trend Analysis, in: Statistical Methods in Water Resources, edited by: Helsel, D. H., USGS, Reston, VA, USA, 323-356, 2002.

Hong, Y., Adler, R. F., Hossain, F., Curtis, S., and Huffman, G. J.: A first approach to global runoff simulation using satellite rainfall estimation, Water Resour. Res., 43, W08502, doi:10.1029/2006WR005739, 2007.

IBIS World: Queensland floods: the economic impact, IBIS World, Los Angeles, CA, USA, 2011.

Irving, D.:Obs catalogue, availabel at Dr. Climate: https://drclimate. wordpress.com/obs-catalogue/, last access: 3 March 2016.

Jain, S., and Lall, U.: Floods in a changing climate: Does the past represent the future?, Water Resour. Res., 37, 3193-3205, 2001.

Katz, R.: StatisticalMethods for Nonstationary Extremes, in: Extremes in a changing climate, edited by: AghaKouchak, A., Easterling, D., Hsu, K., Schubert, S., and Sorooshinan, S., Springer, London, 15-37, 2013.

Katza, R. W., Parlangeb, M. B., and Naveauc, P.: Statistics of extremes in hydrology, Adv. Water Resour., 1287-1304, 2002.

Kiem, A. S., Franks, S. W., and Kuczera, G.: Multi-decadal varaibility of flood risk, Geophys. Res. Lett., 30, 1035, doi:10.1029/2002GL015992, 2003. 
Knight, J. R., Folland, C. K., and Scaife, A. A.: Climate impacts of the Atlatic multidecadal oscillation, Geophys. Res. Lett., 33, L17706, doi:10.1029/2006GL026242, 2006.

Liu, Y. Y., Dorigo, W. A., Parinussa, R. M., de Jeu, R. A. M., Wagner, W., McCabe, M. F., Evans, J. P., and van Dijk, A. I. J. M.: Trend-preserving blending of passive and active microwave soil moisture retrievals, Remote Sens. Environ., 123, 280-297, doi:10.1016/j.rse.2012.03.014, 2012.

McCabe, G. J. and Palecki, M. A.: Multidecadal climate variability of global lands and oceans, Int. J. Climatol., 26, 849-865, 2006.

Nasri, B., El Adlouni, S., and Ouarda, T. B.: Bayesian Estimation for GEV-B-Spline Model, Open J. Stat., 3, 118-128, 2013.

NCAR UCAR: Atmospheric Reanalysis, available at NCAR UCAR Climate Data Guide: https://climatedataguide.ucar.edu/climate-data/ atmospheric-reanalysis-overview-comparison-tables, last access: 3 March 2016.

Newmont Mining Corporation: Creating Value and Improving Lives - 2015 Annual Report and Form 10-K, Newmont Mining Corporation, Greenwood Village, USA, 2016.

Nicholson, S. E. and Kim, J.: The relationship of the El NiñoSouthern oscillation to African rainfall, Int. J. Climatol., 17, 117135, 1997.

NOAA ESRL: Twentieth Century Reanalysis (V2c): 4-times Daily and Daily Average Monolevel, available at NOAA Earth System Research Laboratoy: http://www.esrl.noaa.gov/ psd/data/gridded/data.20thC_ReanV2c.monolevel.html, last access: 3 March 2016.

Padoan, S. and Wand, M.: Mixed model-based additive models for sample extremes, Stat. Probabil. Lett., 78, 2850-2858, 2008.

Princeton Land Surface Hydrology Group: Current Conditions, Experimental Global Water Cycle and Drought Monitor, http://hydrology.princeton.edu/ justin/research/project_global_ monitor/index_global.html, last access: 24 February 2017.

Rajczak, J., Kotlarski, S., and Schär, C.: Does Quantile Mapping of Simulated Precipitation Correct for Biases in Transition Probabilities and Spell Lengths?, J. Climate, 29, 1605-1615, 2016.

Regan, J.: UPDATE 3-Tally of Australia's coal loss from summer floods gets worse, available at Reuters: http://af.reuters.com/ article/metalsNews/idAFL3E7EV48220110401, last access: 1 April 2011.

Rio Tinto: Rio Tinto Annual report 2015, Rio Tinto, Melbourne, Australia, 2016.

Risbey, J. S., Pook, M. J., McIntosh, P. C., Wheeler, M. C., and Hendon, H. H.: On the remote drivers of rainfall variability in Australia, Mon. Weather Rev., 137, 3233-3253, 2009.

Sheffield, J. and Wood, E. F.: Characteristics of global and regional drought, 1950-2000: Analysis of soil moisture data from off-line simulation of the terrestrial hydrologic cycle, J. Geophys. Res., 112, D17115, doi:10.1029/2006JD008288, 2007.

Smith, C. A., Compo, G. P., and Hooper, D. K.: Web-based Reanalysis Intercomparison Tools (WRIT) for analysis and comparison of reanalyses and other datasets, B. Am. Meteorol. Soc., 95, 1671-1678, 2014.

TD Securities: Barrick Gold - Feb 23 2015, TD Securities, Toronto, 2016a.
TD Securities: Newmont Mining Corp., 19 Feb. 2016, TD Securities, Toronto, 2016b.

TD Securities: Agnico Eagle - Feb 11 2016, TD Securities, Toronto, 2016c.

TD Securities: B2Gold - Mar 17 2016, TD Securities, Toronto, 2016d.

TD Securities: Capstone Mining - Apr 05 2016, TD Securities, Toronto, 2016e.

TD Securities: Jan 01 2016, TD Securities, Toronto, 2016 f.

TD Securities: First Quantum Mineral - Mar 11 2016, TD Securities, Toronto, 2016g.

TD Securities: Franco-Nevada - Mar 13 2016, TD Securities, Toronto, 2016h.

TD Securities: GoldCorp - Feb 26 2016, TD Securities, Toronto, 2016 i.

TD Securities: Hudbay - Jan 20 2016, TD Securities, Toronto, $2016 \mathrm{j}$.

TD Securities: Iamgold - Jan 20 2016, TD Securities, Toronto, 2016k.

TD Securities: Kinross - Mar 31 2016, TD Securities,Toronto, 20161.

TD Securities: Lundin Mining - Jan 22 2016, TD Securities, Toronto, $2016 \mathrm{~m}$.

TD Securities: New Gold - Feb 19 2016, TD Securities, Toronto, 2016n.

TD Securities: Teck Resources - Mar 11 2016, TD Securities, Toronto, 2016o.

Van Niekerk, H. J. and Viljoen, M. J.: Causes and consequences of the Merriespruit and other tailings-dam failures, Land Degrad. Dev., 16, 201-212, 2005.

Verdon, D. C., Wyatt, A. M., Kiem, A. S., and Franks, S. W.: Multidecadal variability of rainfall and streaflow: Eastern Australia, Water Resour. Res., 40, W10201, doi:10.1029/2004WR003234, 2004.

Webby, R., Adamson, P., Boland, J., Howlett, P., Metcalfe, A., and Piantados, J.: The Mekong - Applications of Value at Risk (VaR) and Conditional Value at Risk (CVaR) simulation to the benefits, costs and consequences of water resources development in a large river basin, Ecol. Model., 201, 89-96, 2007.

Woldemeskel, F. M., Sharma, A., Sivakumar, B., and Mehrotra, R.: An error estimation method for precipitation and temperature projections for future climates, J. Gephys. Res., 117, 2156-2202, doi:10.1029/2012JD018062, 2012.

Word Bank: World Bank Commodities Price Data (The Pink Sheet), available at The World Bank: http://www.worldbank.org/ en/research/commodity-markets, last access: 4 April 2016.

WRI: Aqueduct Global maps 2.1: Construction desicion-relevant global water risk indicators, WRI, Washington, D.C., 2015.

Yamout, G. M., Hatfield, K., and Romeijn, E.: Comparison of new conditional value-at-ris-based management models for optimal allocation of uncertain water supply, Water Resour. Res., 43, W07430, doi:10.1029/2006WR005210, 2006.

Yousfi, N. and El Adlouni, S.: Regularized Bayesian estimation for GEV-B-splines model, Stoch. Environ. Res. Risk A., 31, 535550, 2016. 